This document is the Accepted Manuscript version of a Published Work that appeared in final form in Accounts of Chemical Research, copyright (C) American Chemical Society after peer review and technical editing by the publisher. To access the final edited and published work see https:// doi.org/10.1021/acs.accounts.9b00480

FINAL

Acc. Chem. Res.

Special issue "Electrifying Synthesis"

\title{
Multiphase Methods in Organic Electrosynthesis
}

Frank Marken $^{1 *}$, Jay D. Wadhawan ${ }^{2}$

${ }^{1}$ Department of Chemistry, University of Bath, Claverton Down, Bath, BA2 7AY, UK

Email:f.marken@bath.ac.uk

${ }^{2}$ University of Hull, School of Engineering, Cottingham Rd, Kingston Upon Hull HU6 7RX, North Humberside, UK

\section{Conspectus}

With water providing a highly favoured solution environment for industrial processes (and in biological processes), it is interesting to develop water-based electrolysis processes for the synthesis and conversion of organic and biomass-based molecules. Molecules with low solubility in aqueous media can be dispersed/solubilised (i) by physical dispersion tools (by milling, by power ultrasound, or by high shear ultra-turrax processing), (ii) in some cases by pressurising/super-saturation (e.g. for gases), (iii) by adding co-solvents or "carriers" such as chremophor EL, or (iv) by adding surfactants to generate micelles, microemulsions, and/or stabilised biphasic conditions. This review examines and compares methodologies to bring the dispersed or multi-phase system into contact with an electrode. Both the microscopic process based on the individual particle impact as well as the overall electro-organic transformation are of interest. Distinct mechanistic cases for multi-phase redox processes are considered.

Most traditional electroorganic transformations are performed in homogeneous solution with reagents, products, electrolyte, and possibly mediators or redox catalysts all in the same (usually organic) solution phase. This may lead to challenges in the product separation step and in the re-use of solvents and electrolytes. When exploiting aqueous electrolyte media, reagents and products (or even electrolyte) may be present as microdroplets or nanoparticles. Redox transformations then occur during interfacial "collisions" under multiphase conditions or 
within a reaction layer when a redox mediator is present. Benefits from this approach can be (i) the use of highly conducting aqueous electrolyte, (ii) simple separation of products and reuse of electrolyte, (iii) phase transfer conditions in redox catalysis, (iv) new reaction pathways, and (v) improved sustainability. In some cases, a surface phase or phase boundary processes can lead to interesting changes in reaction pathways. Controlling the reaction zone within the multi-phase redox system poses a challenge and methods based on micro-channel flow reactors have been developed to provide a higher degree of control. However, detrimental effects in micro-channel systems are also observed, in particular when considering limited current densities (which can be very low in microchannel multiphase flow) or when developing technical solutions for scale-up of multi-phase redox transformations.

This review describes physical approaches (and reactor designs) to bring multi-phase redox systems into effective contact with the electrode surface, as well as cases of important electroorganic multi-phase transformations. Mechanistic cases considered are "impacts" by microdroplets or particles at the electrode, effects from dissolved intermediates or redox mediators, as well as effects from dissolved redox catalysts. These mechanistic cases are discussed for important multiphase transformations for gaseous, liquid, and solid dispersed phases. Processes based on mesoporous membranes and based on hydrogen-permeable palladium membranes are discussed.
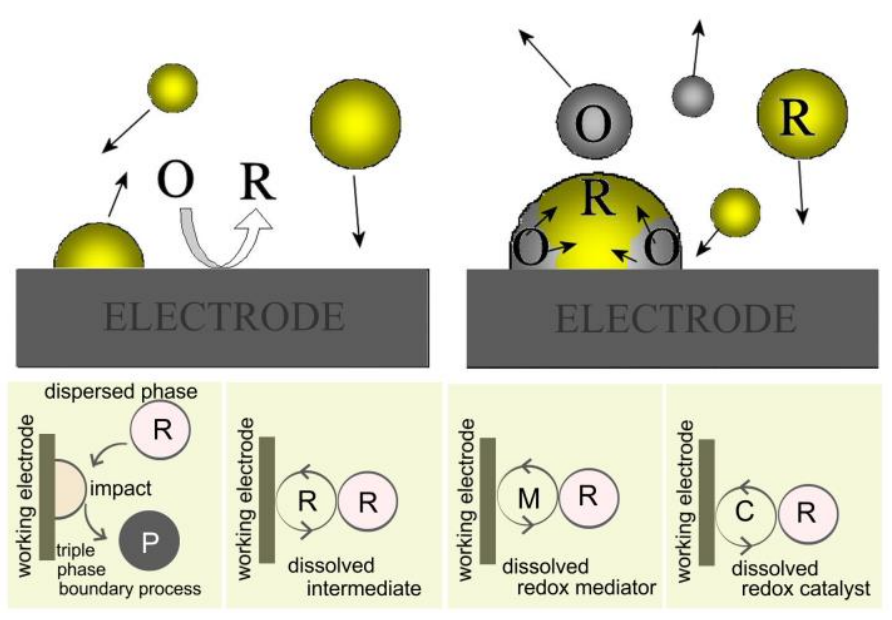


\section{Introduction to Multiphase Electrosynthesis}

Electrosynthesis currently undergoes a phase of rejuvenation due to developments linked to availability of sustainable electricity, ${ }^{1,2,3,4}$ the trend towards robotic synthesis, ${ }^{5}$ and based on renewed interests in elegant transformations performed effectively in simple electrolysis systems and without added reagents, ${ }^{6}$ conversion of biomass to commodity chemicals, ${ }^{7}$ or providing new pathways in cross-coupling. ${ }^{8}$ New approaches to reactor engineering and process design are desirable. ${ }^{9}$ Multiphase methods in organic electrosynthesis are currently not very common, but multiphase phenomena in electrosynthesis can help introducing a reservoir of reagent, providing a sink of product, or controlling the reaction environment. This review summarises some approaches (e.g. types of electrodes, membranes, microfluidics, activation) to multiphase electrosynthesis.

Important examples for multiphase electrosyntheses are carbon dioxide reduction to valuable products, ${ }^{10}$ emulsion electrochemical reactions under surfactant controlled phase-transfer catalysis conditions, ${ }^{11}$ but also surfactant-free emulsion ultrasound-enhanced carbon-carbon coupling chemistry. ${ }^{12}$ Interfaces introduced in the multiphase system can be liquid | gas, liquid | liquid, or liquid | solid nature and these interfaces provide environments for reactions to occur. When considering multiphase electrochemical processes, it is possible to broadly distinguish five mechanistic cases (see Figure 1): (I) with a homogeneous bulk phase a surface phase forms and this may strongly affect the reaction mechanism, (II) the dispersed phase directly "impacts" onto the electrode surface to undergo reaction; (III) an indirect process occurs with partially dissolved reagent diffusing from dispersed phase to electrode; (IV) a redox mediated process occurs with a mediator shuttling electrons between the electrode and the dispersed phase; and (V) a redox catalysed process with a redox active molecule transferring charge and reacting (Figure 1).

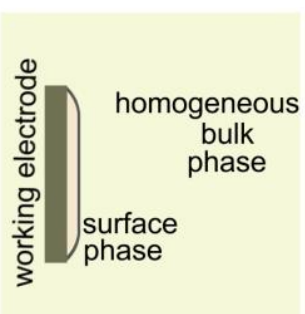

(I)

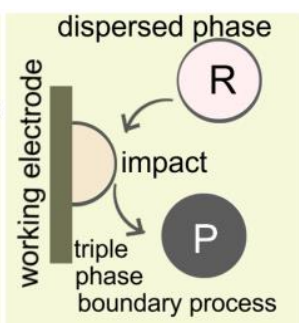

(II)

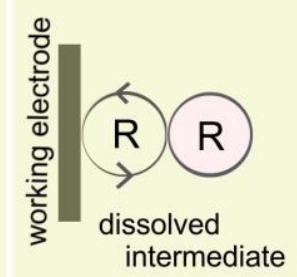

(III)

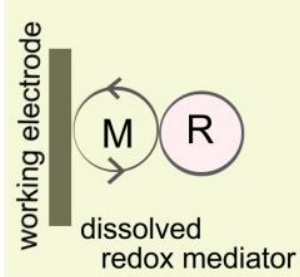

(IV)

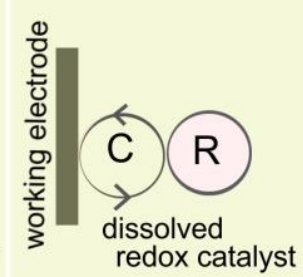

(V)

Figure 1. Schematic drawing for (I) surface phase formation, (II) a dispersed reagent R directly interacting with the electrode surface to give product $\mathrm{P}$, (III) the reagent indirectly interacting with the electrode via dissolved R, (IV) the dispersed reagent reacting with an electron shuttle mediator $\mathrm{M}$, and (V) the dispersed reagent reacting with a redox catalyst which is actively involved in the reaction. 
Although based on a homogeneous bulk phase, case (I) is of significant interest. Recent work by Baran and co-workers beautifully demonstrates the innovation potential for multiphase conditions in electrosynthetic transformations even for well-studied reactions. ${ }^{13}$ Surfacemodified electrodes are shown to allow traditional and novel Birch-type reactions to be performed. A very thin film of additives (see TPPA and DMU in Figure 2) at the working electrode surface (here steel or zinc) is employed to expand the scope of this reaction into nonclassical solution environments such as THF (Figure 2). In this case, the presence of the film offers a modified reaction environment.

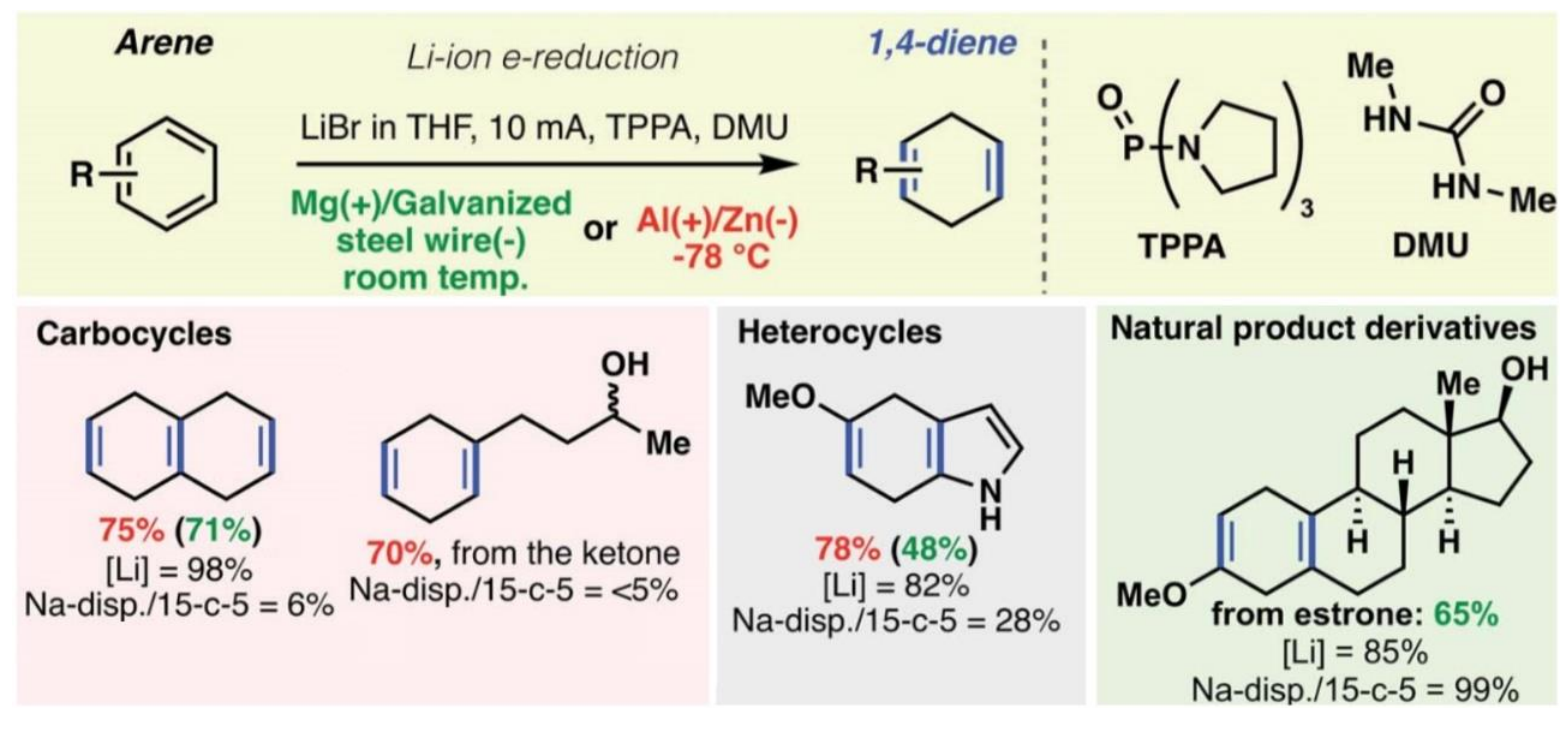

Figure 2. Scope of and examples for the electrochemical (based on steel wire cathode and sacrificial Mg anode or based on $\mathrm{Zn}$ cathode with sacrificial Al anode) Birch reaction, encompassing arenes and heterocycles, and comparison to other modern Birch alternatives (A lithium metal reaction or sodium dispersion conditions). Reproduced with permission from ref. 13. Copyright 2019 AAAS.

The electrochemical Birch reaction allows reagents such as lithium metal or sodium metal dispersions to be replaced with simple steel or zinc electrodes (see Figure 2) with a solvent such as THF and additives (TPPA and DMU) to provide an interfacial layer at the working electrode where the regio-selective reduction/hydrogenation can proceed. The Birch process can be carried out in the presence of alcohol reagents or even in alcohol as co-solvent as long as sufficiently fast mass transport is applied. ${ }^{14}$ The original report for the Birch reduction ${ }^{15}$ in 1946 was based on liquid ammonia solvents. The versatility and practicality of this newly developed "surface-phase" Birch reduction (see Figure 2) in THF offers new opportunities. Other types of organic electrosynthesis reactions can also benefit from "surface-phase" or surface layer reaction conditions. For example, the recently by Waldvogel and coworkers developed phenol cross-coupling at boron-doped diamond anodes immersed in fluoroalcohol-alcohol solvent mixtures (see Figure 3). ${ }^{16}$ 


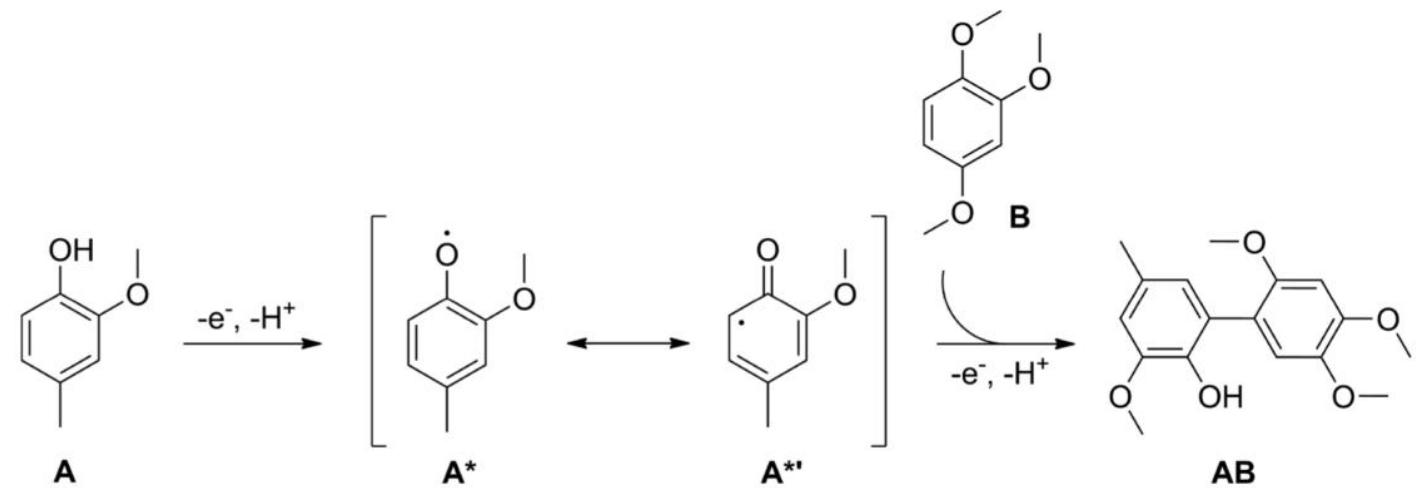

Figure 3. Reaction scheme for the electroorganic cross-coupling of phenol $\mathbf{A}$ in the presence of $\mathbf{B}$ surface enriched in a 1,1,1,3,3,3-hexafluoro-propan-2-ol/methanol solvent mixture at a boron-doped diamond electrode. Reproduced with permission from ref. 16. Copyright 2019 American Chemical Society.

In addition to the surface phase approach with homogeneous bulk solution, also multi-phase systems with a dispersed phase can be beneficial in electro-organic transformations. A classic electrosynthetic reaction such as the Birch reduction can be carried out effectively in a stirred one-pot reactor and with all reagents dissolved homogeneously. However, there are many cases, in which reagents are not readily soluble. In particular when using aqueous electrolysis conditions (or "green" conditions ${ }^{17,18,19}$ ) or multiphase electrolysis including micro-emulsion conditions. ${ }^{20}$ Multiphase electrosynthesis can be both green and practical (see for example the Monsanto process for Nylon production ${ }^{21,22}$ ). In addition, making the interaction of the dispersed phase with the electrode surface effective, offers an intriguing physico-chemical challenge of electrode surface design. Similar to the case of the homogeneous Birch reduction example in Figure 1, the conditions at the interface of working electrode and dispersed reagent are crucial in achieving selectivity and a high rate of conversion.

Direct Processes. The dispersed phase can interact "directly" with the electrode surface as suggested in case II in Figure 1. Oil microdroplets and in particular solid particles and nanoparticles are readily dispersed into aqueous media and propelled by Brownian motion or agitation. Organic nanoparticles attract attention based on reactivity different from that of solutions or bulk solids. ${ }^{23}$ Recent studies have shown that single entity or nanoparticle "impacts" are possible at microelectrodes to reveal individual events ${ }^{24,25,26,27,28}$ for inorganic nanoparticles, but also for organic particles based on indigo, ${ }^{29} \mathrm{DPPH},{ }^{30}$ and for oil blue dye $\mathrm{e}^{31}$ (Figure 4). Redox active colloids for energy storage with "impact charging" have been proposed based on organic redox systems. ${ }^{32}$ Information from impact voltammograms are considerable with each "spike" revealing time-dependent details about size, charge, interaction with the electrode, type of electron transfer, and chemical transformation pathways. Due to the stochastic nature of these single-entity or impact voltammograms, each can be analysed individually and data analysis has to be based on statistical tools linked to computational models. 


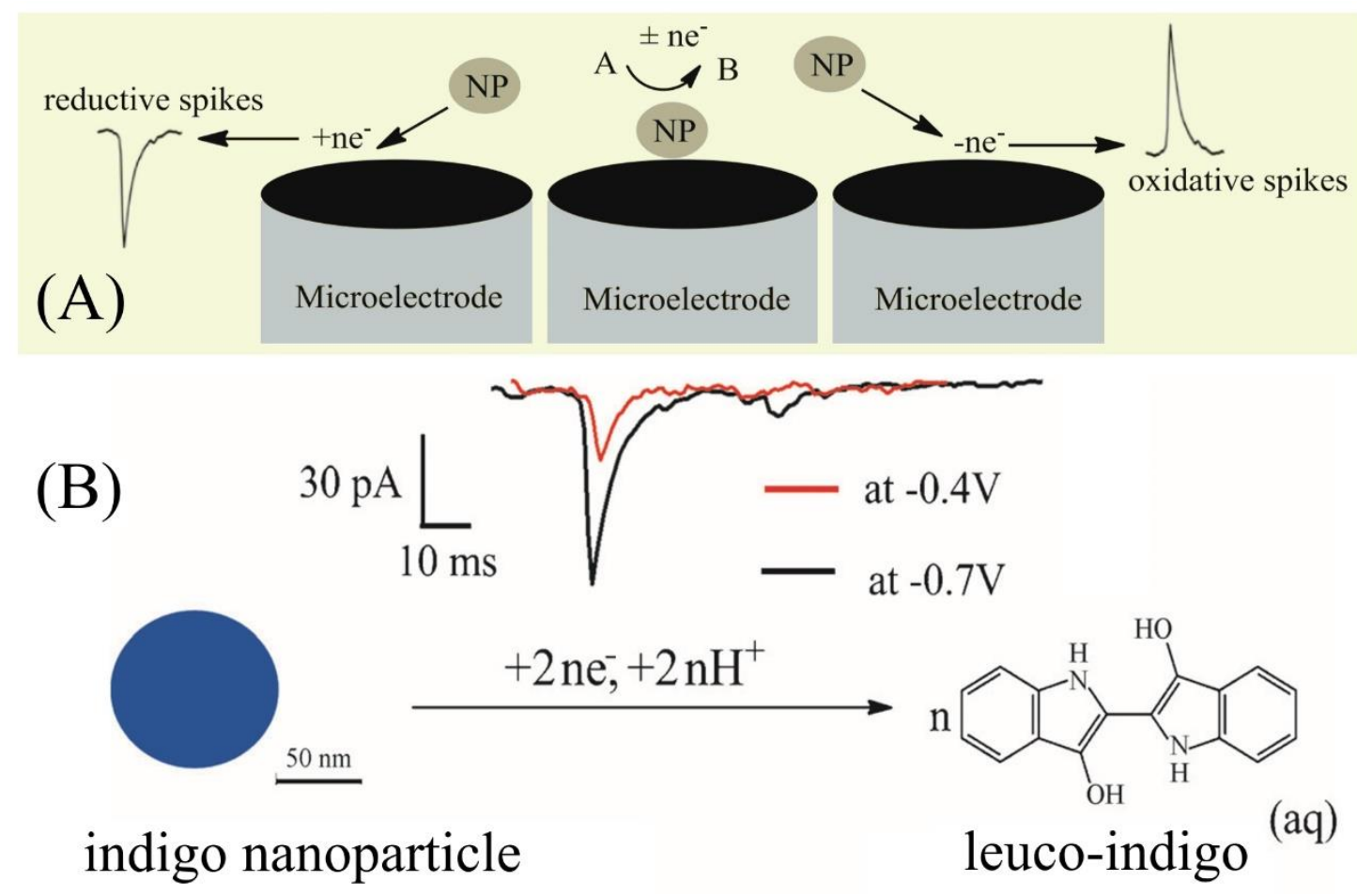

Figure 4. (A) Schematic description of nanoparticle "impacts" leading to reductive of oxidative current spikes. Reproduced with permission from ref. 25 (Copyright 2014 Elsevier). (B) Impact chronoamperometry data for indigo nanoparticle reduction upon impact. Reproduced with permission from ref. 29 (Copyright 2014 Wiley).

Single entity voltammetry has also been demonstrated for aqueous solutions of vesicles containing drugs ${ }^{33}$ or redox probes. ${ }^{34}$ Vesicular transport is an important natural process and linked to in vivo neurotransmitter detection. ${ }^{35,36}$ Individual vesicles or liposomes can be studied and counted. ${ }^{37,38,39}$

Although impacts in electrochemistry clearly work, the lower diffusion coefficient for these particles often severely limits the overall efficiency of direct electrochemical conversion of solids dispersed in solution even with vigorous agitation. For solid-to-solid redox transformations there are further problems with propagation of the reaction into the solid material. Ultrasound can be employed to enhance transport for solid particles ${ }^{40}$ and for dispersed droplets. ${ }^{41}$ The high shear conditions under ultra-turrax agitator conditions have been exploited to generate a surfactant-free dispersion and to enhance the interaction with the electrode surface. ${ }^{42}$ In Figure 5 the experimental design and a typical voltammogram for oil droplets containing n-butylferrocene are shown. 


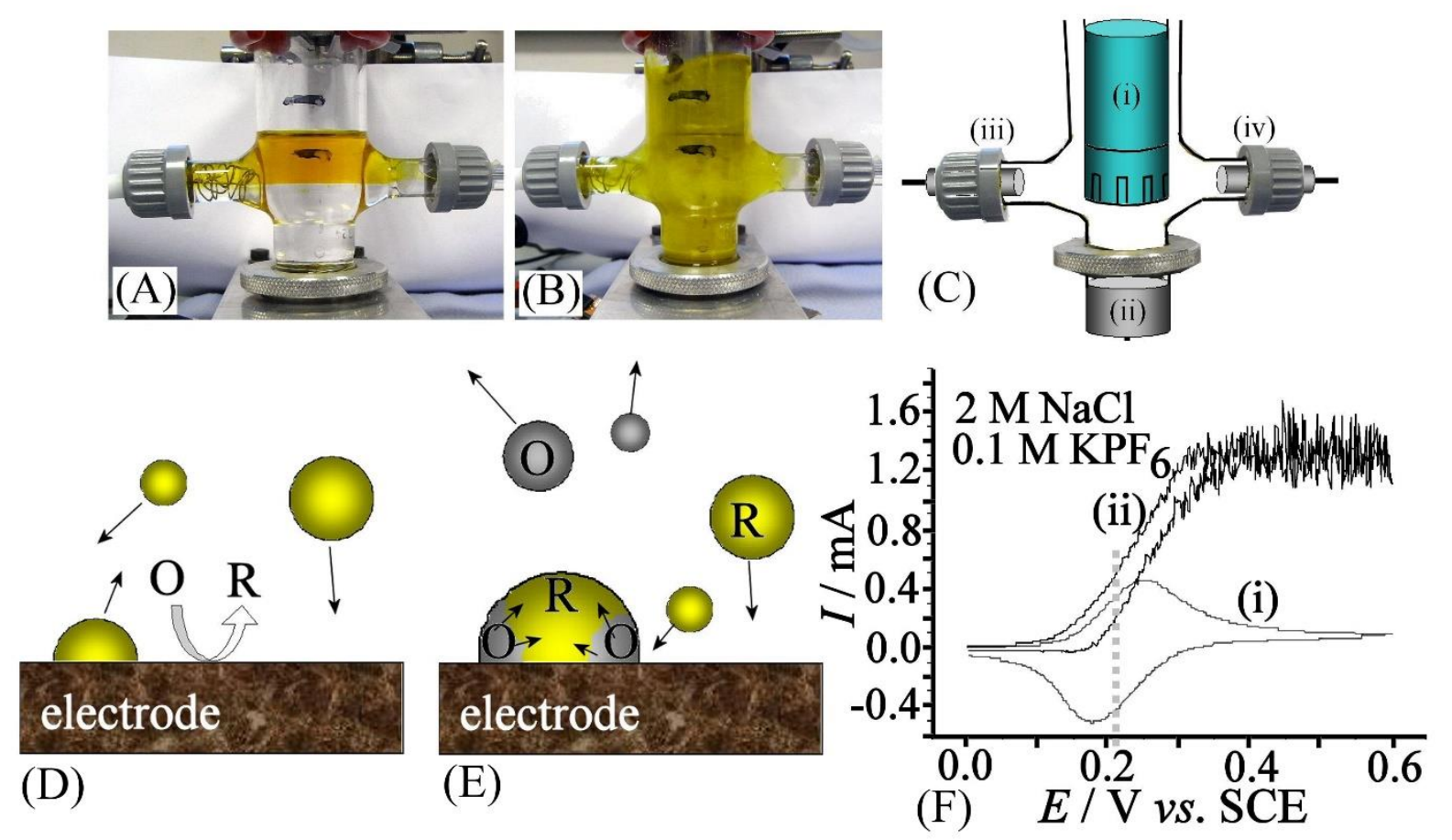

Figure 5. Electrolysis cell for ultra-turrax emulsification (A) before and (B) during operation. (C) Schematic drawing of components (i) ultra-turrax insert, (ii) working electrode, (iii) counter electrode, and (iv) reference electrode. (D) Schematic drawing of the reaction conditions with organic microdroplets (containing yellow nbutylferrocene) interacting with the surface and reacting via dissolution and electron transfer in the aqueous phase or (E) at the triple-phase boundary organic | aqueous | electrode. (F) Typical voltammogram for the oxidation of n-butylferrocene in acetonitrile (i) without and (ii) with ultra-turrax agitation. The presence of $\mathrm{KPF}_{6}$ defines the oxidation potential due to transfer of $\mathrm{PF}_{6}^{-}$from the aqueous into the organic phase during oxidation. Reproduced with permission from ref. 42. Copyright 2010 Elsevier.

For processes which are dominated by the triple phase boundary reaction (see Figure 5E), the rate remains low even with ultra-turrax agitation. However, interfacial effects for example introduced by metal cations can substantially increase the flow of current in direct biphasic reactions. Amatore and coworders reported the direct electroreduction of benyzlhalides to give bibenzyl. ${ }^{43}$ The cathode material was optimised to lower hydrogen evolution and a sacrificial anode based on aluminium was employed. Perhaps surprisingly, the resulting aluminium cations from the anode were shown to enhance the cathodic reaction. The mechanism was proposed to be based on radical intermediates that are formed close to the solid | liquid | liquid interface.

Ultrasound as a dispersion and agitation tool can be employed in multiphase electrosynthesis. Ultrasound as a methodology in emulsion electrosynthesis ${ }^{44}$ has been employed effectively by Atobe and coworkers in the oxidation of emulsion droplets of water-insoluble amines to nitriles $^{45}$ and in the electro-polymerisation of emulsion monomers (e.g. employing 3,4ethylenedioxythiophene or EDOT to form PEDOT) to give high quality deposits. ${ }^{46}$ Figure 6 shows the sono-emulsification for EDOT employing a sequence of frequencies to create ever smaller emulsion droplets for electro-polymerization. 


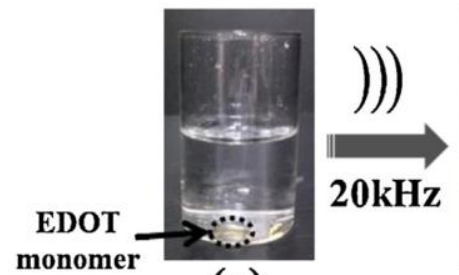

(a)

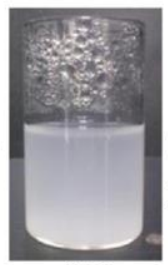

(b)

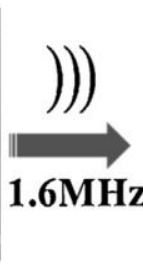

$.6 \mathrm{MHz}$

(c)

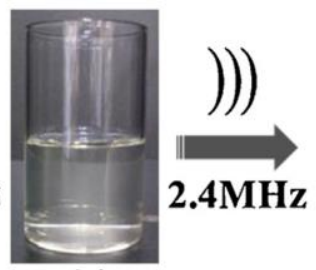

c)

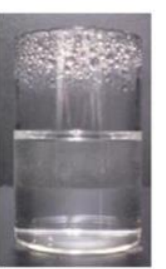

(d)

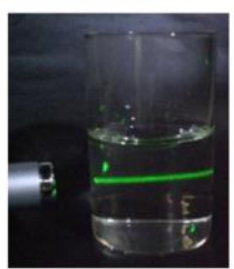

(e)

Figure 6. Photographs of the tandem acoustic emulsification treatment of EDOT monomer in aqueous $1 \mathrm{M}$ $\mathrm{LiClO}_{4}$. (a) EDOT/aqueous solution mixture. Emulsification after (b) $20 \mathrm{kHz}, 5 \mathrm{~min}$, (c) $20 \mathrm{kHz}, 5 \mathrm{~min}$ followed by $1.6 \mathrm{MHz}, 5 \mathrm{~min}$, and (d) $20 \mathrm{kHz}, 5 \mathrm{~min}$ followed by $1.6 \mathrm{MHz}, 5 \mathrm{~min}$ and $2.4 \mathrm{MHz}, 5 \mathrm{~min}$. (e) Photograph of the Tyndall scattering effect for a green laser in the emulsified solution prepared by three-step sonication. Reproduced with permission from ref. 46. Copyright 2013 Elsevier.

The use of ultrasound in Kolbe electrolysis ${ }^{47}$ is illustrated in Figure 7. A one-compartment cell is employed with steel cooling coil, ultrasonic horn emitter, an embedded working electrode opposite to the ultrasonic horn, and counter/reference electrodes placed side-wise. The dispersed organic phase (hexanoic, heptanoic, or lauric acid) forms a biphasic system in aqueous $1 \mathrm{M} \mathrm{NaOH}$ with power ultrasound directed at the working electrode. Electrolysis products were alkanes (3) and esters (4) with EPR evidence pointing towards unexpected dimeric peroxo reaction intermediates.

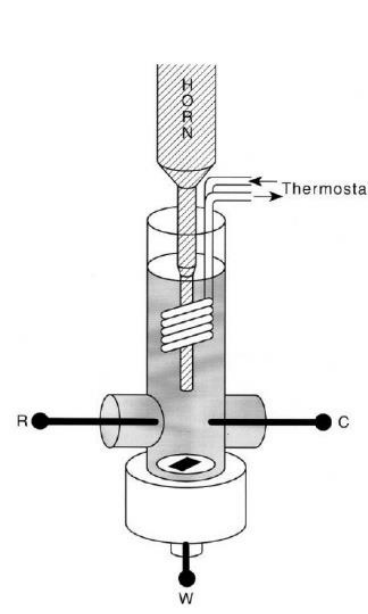

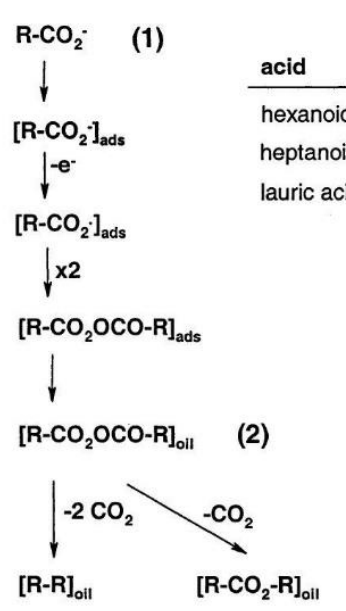

(3)

(4)
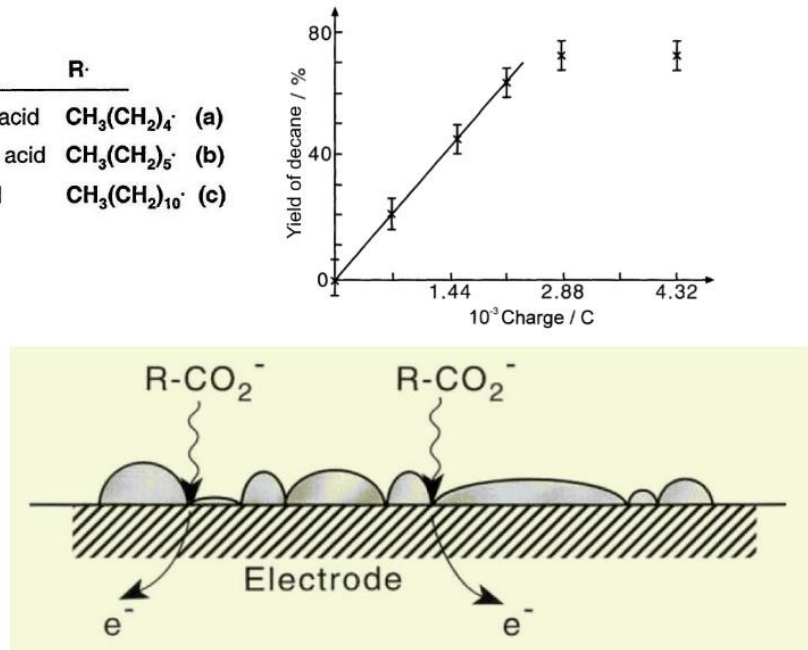

Figure 7. Schematic drawing of the experimental set-up for the biphasic sono-Kolbe electrolysis. The reaction scheme shows the mechanistic pathway with the dimer (3) the main Kolbe product. The schematic drawing shows conditions at the electrode surface during electrolysis and a plot of decane yield versus time. Reproduced with permission from ref. 47. Copyright 2001 Elsevier.

Often direct multiphase reactions (see Figure 1 case II) remain low yielding and therefore, redox mediators are sometimes desirable to more effectively shuttle electrical charge from the 
electrode surface to the dispersed reagent. One particular case here is indirect multiphase reaction or "self-mediation" based on partially soluble reagents (Figure 1, case III).

Indirect Processes. Many organic molecules (depending on polar functional groups) can partition into the aqueous phase. In the case of microemulsion reactions, this solution phase partitioning offers a pathway for electrolysis (see Figure 1 case III). After redox conversion products from electrolysis may either be more aqueous soluble to stay in solution or less aqueous soluble to partition back into the dispersed oil phase. This mechanism is very common $^{48,49}$ and associated with many biphasic processes and sono-electrosynthesis reactions including olefin reduction, heterocycle hydrogenation, and Kolbe electrolysis.

An example for indirect electrolysis of methoxybenzene derivatives under biphasic conditions is the anodic aromatic cyanation process with $\mathrm{NBu}_{4} \mathrm{CN}$ as phase transfer reagent carried out in a single compartment cell. ${ }^{50}$ When compared to the homogeneously performed reaction (only product A forms, see Figure 8), new products (products B and C) are observed and the mechanism for this is discussed.

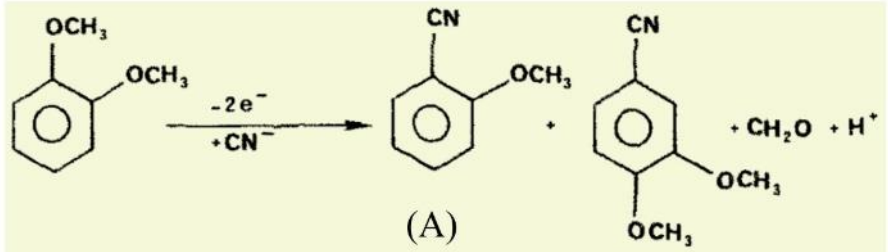

(B)

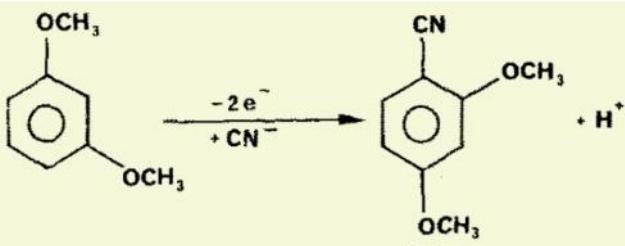

(C)

Figure 8. Reaction pathways for ortho- and meta-dimethoxybenzene at the anode and in the presence of cyanide anions. Reproduced with permission from ref. 50. Copyright 1984 Elsevier.

In some cases the product from the redox conversion (e.g. formation of leuco-indigo from indigo) can be more aqueous-soluble and trigger a "self-mediation". ${ }^{51}$ This can be exploited for a much cleaner process with less reagents/impurities ${ }^{52}$ as long as an initial low level of leuco-indigo is present. The methodology has been employed for a wider range of insoluble vat dyes. ${ }^{53} \mathrm{~A}$ further example for self-mediated electrosynthesis is the reduction of grey selenium powder to give $\mathrm{Se}_{2}{ }^{2-}$ or $\mathrm{Se}^{2-}$ in solution, ${ }^{54}$ which then reacts further with alkylhalides to give dialkyldiselenides or dialkylselenides. Similar reactivity exists for sulphur and tellurium. ${ }^{55}$

Redox Mediation. A vast range of organic electrosynthetic transformations are based on redox mediators (Figure 1, case IV). ${ }^{56}$ Many of these mediators could be applicable in dispersions and emulsions, but much less work has been done on these multiphase systems. Redox mediators in nature are common, for example in photosynthesis where ubiquinols and plastoquinols shuttle charges in the thylakoid membrane. ${ }^{57,58}$ 
For electrosynthetic processes, alizarin red $\mathrm{S}$ is a good mediator (two-electron, two-proton) for the reduction of aqueous indigo particle suspensions ${ }^{59}$ but also for other solid anthraquinone derivatives. ${ }^{60}$ The selective six-electron reduction of nitroarenes to aromatic amines has been demonstrated with aqueous-soluble titanocene derivatives. ${ }^{61}$ This process is performed in separate in-cell electrolysis and ex-cell biphasic redox conversion (Figure 9).

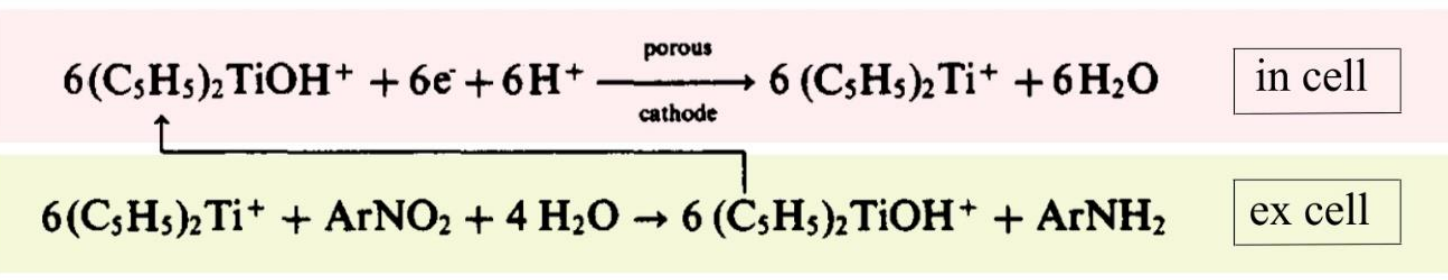

Figure 9. Reaction pathway for titanocene(IV) cations in water being reduced to titanocene(III) followed by biphasic reduction of nitroaromatic compounds to aminoaromatic products. Reproduced with permission from ref. 61. Copyright 1997 Elsevier.

Redox Catalysis. In addition to mediating or electron-shuttling, redox active mediator molecules may undergo reactions or provide catalytic reactivity (Figure 1, case V). The benefits of employing an aqueous electrolysis phase with dispersed reagents has been recognised in particular for "green" processes. In a review by Tanaka and Kuroboshi and Mitsudo ${ }^{62}$ opportunities from this approach are clearly explained. An example of electrochemically driven Diels-Alder reactions carried out in aqueous emulsion systems with electrogenerated "unstable" ortho-quinones ${ }^{63}$ is illustrated in Figure 10.

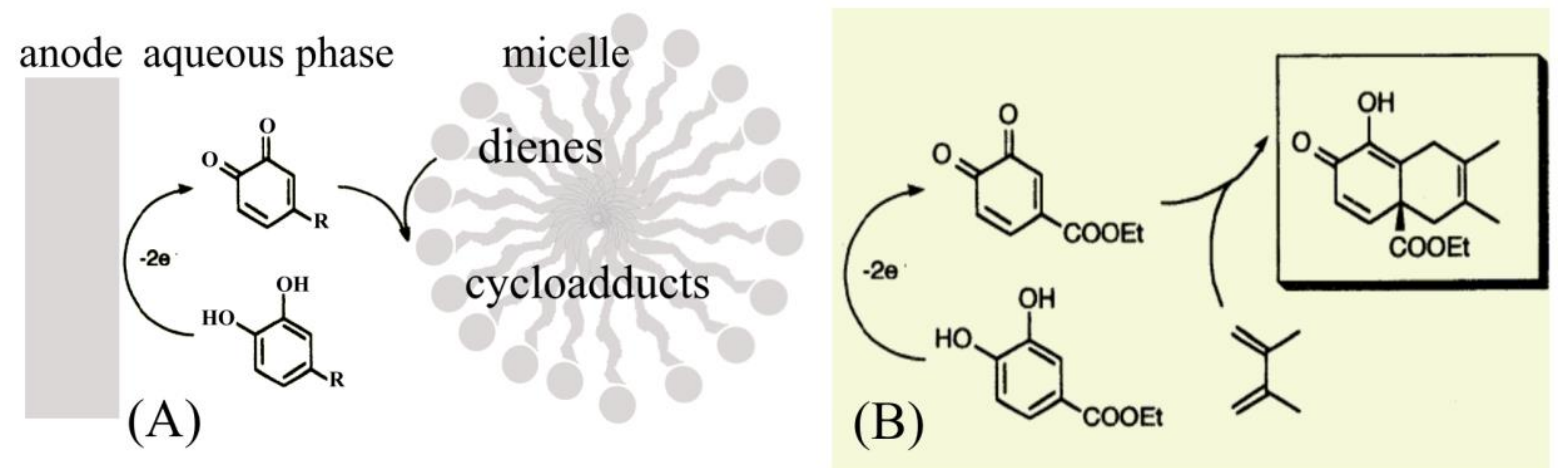

Figure 10. (A) Schematic drawing for oxidation of ortho-quinols to reactive ortho-quinones for Diels Alder addition in micellar media. (B) Typical reaction sequence.

A further example for redox catalysis is the $\mathrm{Ni}(\mathrm{II})-2,2$ '-bipyridine catalysed emulsion electrolysis to give homo-coupling of arylhalides. ${ }^{64}$ Surfactants were employed and different types of reactors were investigated to convert arylbromides to biaryls. Emulsion synthesis of benzaldehyde from benzylalcohol ${ }^{65}$ was demonstrated based on the hypochlorite driven 
Montanari reaction, ${ }^{66,67}$ which could also be performed by electrochemical methods (see Figure 11) with an aqueous bromide/hypobromide redox mediator. Tang and coworkers also attempted the immobilization of the TEMPO/TEMPO ${ }^{+}$catalyst directly within the magnetic nano-particulate Pickering surfactant to maximise the re-use of the redox catalyst.

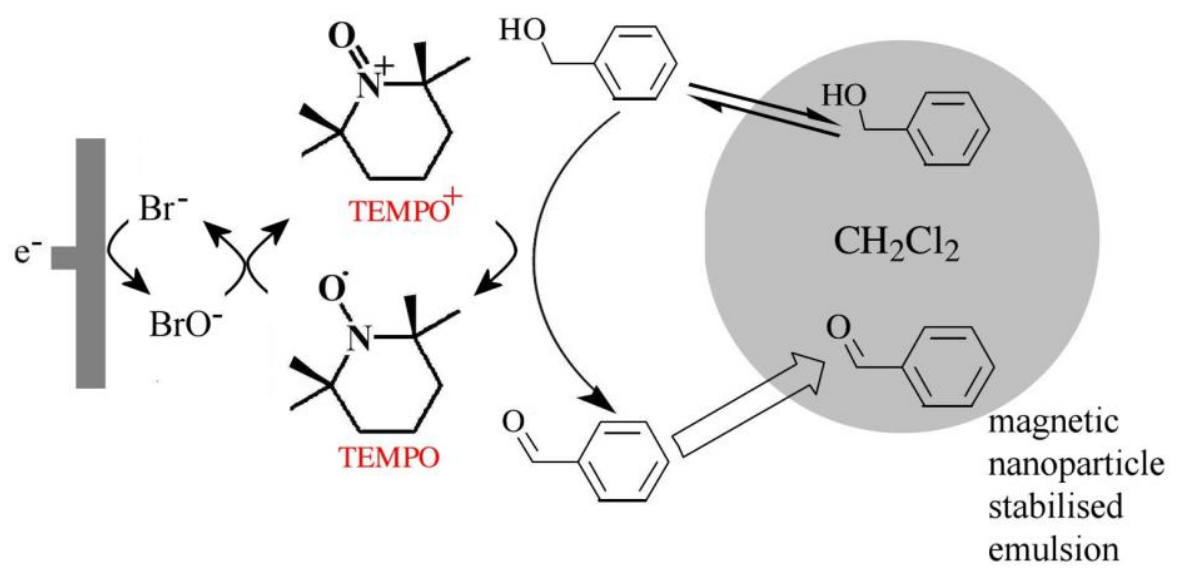

Figure 11. Redox mediator chain with TEMPO as active redox catalyst. Schematic drawing of the benzylalcohol to benzaldehyde transformation under emulsion conditions.

A microemulsion electro-organic transformation based on redox catalysis ${ }^{68}$ and for a natural redox catalyst vitamin $\mathrm{B}_{12}{ }^{69}$ is shown in Figure 12. Rusling and coworkers employed didodecyl-dimethyl-ammonium bromide surfactant and dimethyl-formamide-water microemulsion conditions. The process was optimized to give close to $100 \%$ yield in dibenzyl without toluene side products. Vitamin $\mathrm{B}_{12}$ redox catalysis was also employed in sonoemulsion electrolysis. ${ }^{22}$ In order to explore further examples of multiphase electrosyntheses, a range of different cases of multiphase systems will be considered separately based on gas, liquid, and solid dispersions.

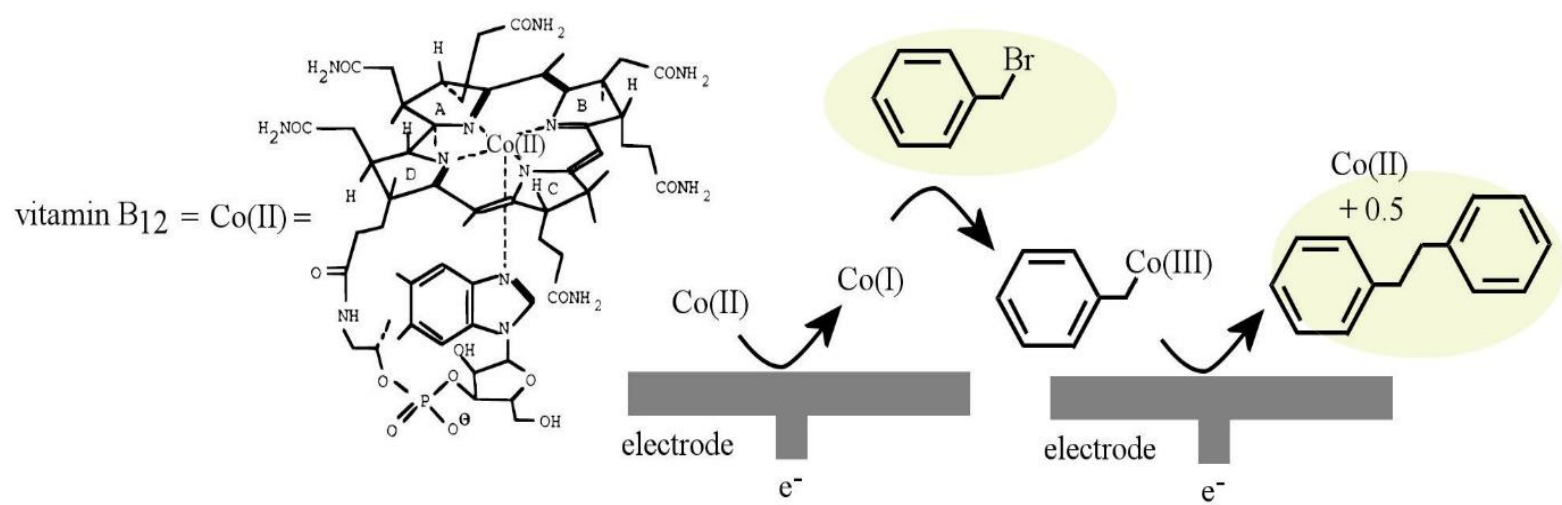

Figure 12. Molecular structure of vitamin $B_{12}$ and schematic description of the consecutive 2-electron reduction leading to biphenyl. Reproduced with permission from ref. 69. Copyright 1996 American Chemical Society. 


\section{Solid | Liquid | Gas Systems}

A classic case of gas-based electrosynthetic process is the reduction of carbon dioxide. The aqueous solubility of carbon dioxide is relatively low and therefore process intensification is linked to bringing more $\mathrm{CO}_{2}$ to the electrode/catalyst surface in contact to the electrolyte. The more efficient electrocatalytic reduction of $\mathrm{CO}_{2}$ to $\mathrm{CO}$ on nano-structured gold-nanopolyethylene interfaces has been reported by Cui and coworkers. ${ }^{70}$ In a similar study focusing on reactor design and gas diffusion electrodes for $\mathrm{CO}_{2}$ reduction Wessling and coworkers have compared reactivity in different reactor types ${ }^{71}$ with silver gas diffusion electrodes giving carbon monoxide and copper gas diffusion electrodes giving ethylene as gaseous products (Figure 13A).

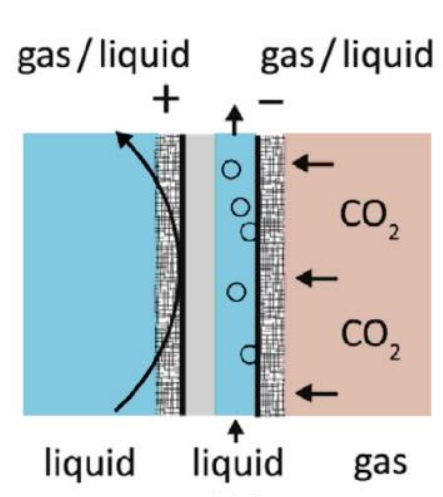

(A)

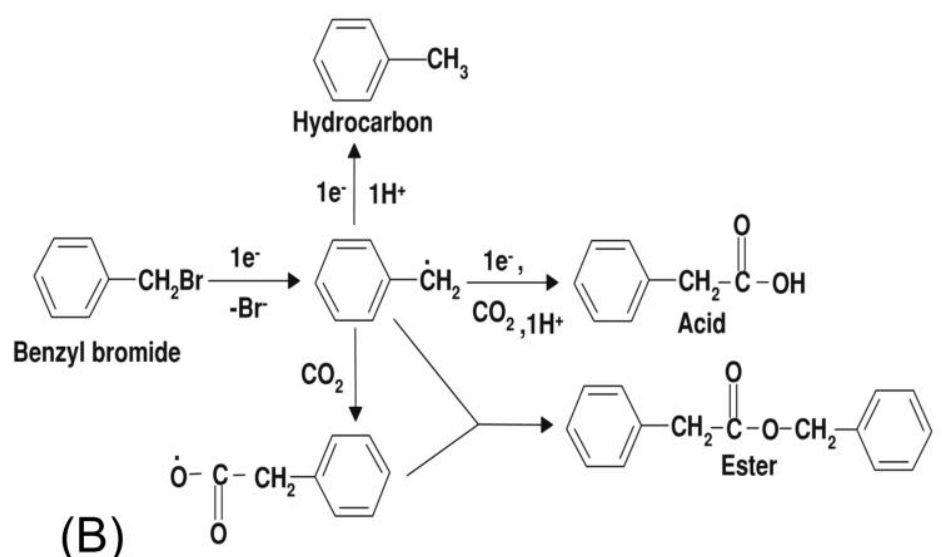

Figure 13. (A) A membrane gas diffusion reactor design with gaseous $\mathrm{CO}_{2}$ feed. Reproduced with permission from ref. 71 (Copyright 2019 Elsevier). (B) Schematic description of electrocarboxylation in aqueous CTAB bicontinuous microemulsion. Reproduced with permission from ref. 72. Copyright 2009 Elsevier.

In contrast to the direct electroreduction of gaseous carbon dioxide, it is possible to employ emulsion-electrosynthesis to capture and chemically bind $\mathrm{CO}_{2}$ into carboxylates. Noel and coworkers $^{72}$ developed a process for electrocarboxylation in emulsion during reduction of arylhalides and benzylhalides (see Figure 13B).

Instead of exploiting the properties of gas diffusion electrodes, it is possible to exploit gas permeability for specific types of membrane materials. In particular palladium and palladium alloys are known to allow hydrogen diffusion (with room temperature diffusivities ${ }^{73}$ of approx. $10^{-11} \mathrm{~m}^{2} \mathrm{~s}^{-1}$ ) and therefore hydrogen generating electrosynthetic reactions can be coupled to hydrogen consuming processes through a thin film of palladium metal. The transit time for hydrogen through a $10 \mu \mathrm{m}$ thickness palladium film is approximately $\tau=\delta^{2} / D=10 \mathrm{~s}$ and therefore practical in electrosynthesis. Berlinguette and coworkers have demonstrated this by coupling alcohol oxidation to alkyne reduction ${ }^{74,75}$ (Figure 14). This type of membrane reactor does allow hydrogenation/reduction in non-conducting (no electrolyte) or even gaseous conditions in the "chemical compartment" and is therefore a mechanistic case comparable to that of multiphase electrosynthesis. However, in this case the different phases are separated by the palladium membrane and do not actually mix. 


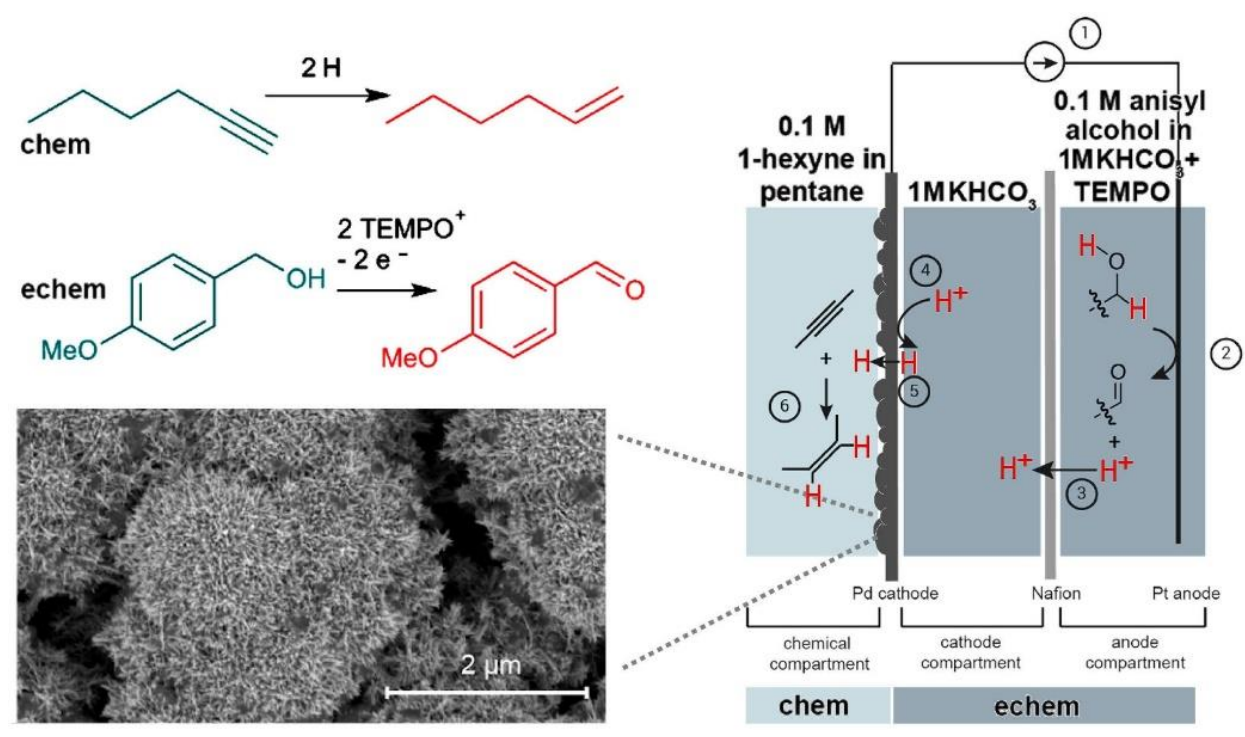

Figure 14. Illustration of multiphase palladium membrane reactor. (1) Current is applied to the palladium electrode; (2) Mediated oxidation of an alcohol to an aldehyde; (3) Released protons cross a Nafion proton exchange membrane; (4) Protons are reduced resulting in hydrogen adsorption into the palladium foil; (5) Diffusion through the palladium; (6) Hydrogenation at the high surface area palladium modified surface (see SEM). Reproduced with permission from ref. 74. Copyright 2017 Nature.

The use of palladium membranes in related reactors and in catalytic hydrogenation is well known. Shirai et al. reported hydrogenation of furan. ${ }^{76}$ Gryaznov reported on surface catalytic properties for palladium alloys ${ }^{77}$ and production of ultra-pure chemicals based on hydrogen permeation through palladium. ${ }^{78}$ Also the reduction of carbon dioxide at a hydrogen permeable palladium-ruthenium alloy coated with nickel has been observed. ${ }^{79}$ Innovative applications of palladium membranes have been reviewed. ${ }^{80}$

Related types of membrane electrosynthesis have been reported also on ionomer membranes with metallic electrodes on the surface. Electrolysis in non-conducting fluids is possible with solid polymeric electrolytes. ${ }^{81}$ Electrolysis in electrolyte salt-free solutions has been reported. ${ }^{82}$ The dechlorination of 4-chlorotoluene in a two-compartment electrolysis cell separated by a palladised ion exchange membrane has been realised. ${ }^{83,84} \mathrm{~A}$ short review has appeared on the potential and applications of ionomer membranes in organic electrosynthesis. ${ }^{85}$ Ogumi and coworkers also contributed to the development of solid polymer electrolysis for organic synthesis ${ }^{86}$ and hydrogenation at solid polymer membranes driven by electrochemistry ${ }^{87}$ has been reported.

\section{Solid | Liquid | Liquid Systems}

The application of electrode | liquid | liquid electrosynthesis has considerable practical significance. ${ }^{88}$ The case of organic water-immiscible droplets dispersed in aqueous electrolyte media is the most common type of multiphase electrosynthesis application. There are examples 
of direct, indirect, redox mediated, and redox catalysed processes. Voltammetric studies on immobilised microdroplets ${ }^{89}$ provide an insight into reactivity and mechanism for processes associated with microdroplets immobilised on electrode surfaces.

Microfluidic systems offer powerful tools for organic electrosynthesis ${ }^{90,91,92}$ and liquid | liquid double-flow system for biphasic conditions have been developed. Both microdroplet flow ${ }^{93}$ and continuous channel flow ${ }^{94,95,96}$ are possible. Channel flow was introduced to achieve a better-defined dynamic solid | liquid | liquid interface. ${ }^{97}$ Figure 15 shows the double channel design and data for the oxidation of n-butylferrocene in $N$-octyl-pyrrolidone flowing next to aqueous $0.1 \mathrm{M} \mathrm{NaClO}_{4}$ electrolyte. The oxidation of the n-butylferrocene occurs at the triple phase boundary and electron transfer from gold electrode to organic phase is associated with a simultaneous transfer of a perchlorate anion from the aqueous into the organic phase. This allows charge neutrality to be maintained, but this also leads to a particular reactivity pattern with a wedge-shaped product diffusion zone (Zone 1) moving into the flow direction.
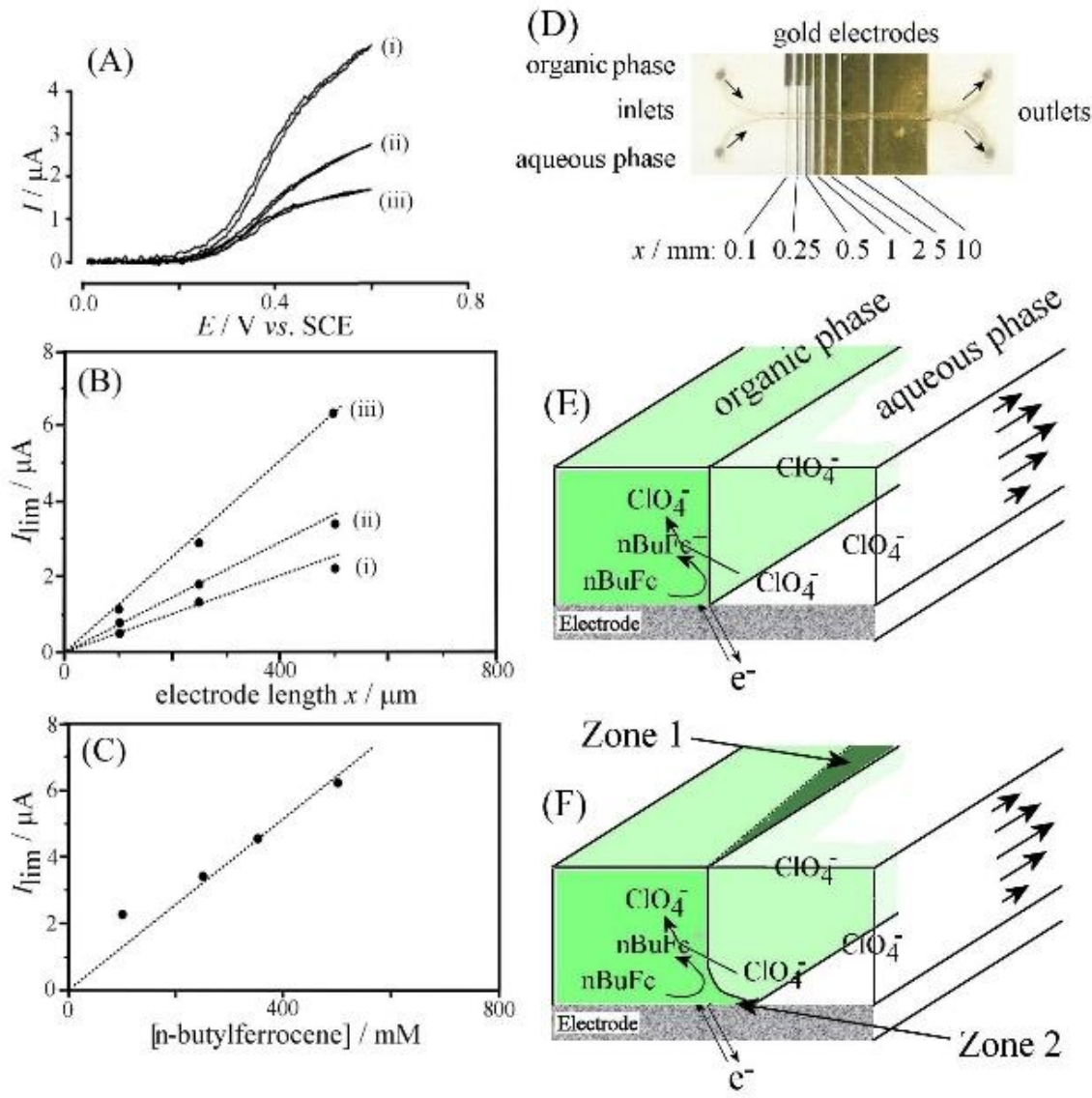

Figure 15. Biphasic voltammetry for the oxidation of n-butylferrocene in the flowing organic phase in contact to a flowing aqueous electrolyte phase. (A) Voltammograms obtained under flow conditions with plots for limiting current versus electrode length (B) and limiting current versus n-butylferrocene concentration (C). (D) Photograph of the biphasic flow system with gold working electrodes within the channel. (E) Schematic drawing of the twophase flow with electron transfer and ion transfer in the triple phase boundary region. (F) Schematic drawing of the inter-diffusion region (zone 1) causing a current increase at lower flow rates. Reproduced with permission from ref. 97. Copyright 2007 Elsevier. 
A more practical or scaled-up implementation of biphasic flow electrolysis can be based on metal foam electrodes. Two-phase electrolysis can be achieved by using a metallic foam to flow both phases through. The oxidation of benzylalcohol has been studied ${ }^{98}$ with the aim to enhance the yield of benzaldehyde. The addition of organic solvent to the biphasic reaction mixture was shown to improve performance. Another interesting type of porous electrode structure for biphasic electrolysis is "bucky-paper" based on carbon nanotubes. ${ }^{99,100}$ Figure 16 shows typical scanning electron microscopy images of the commercial approximately $150 \mu \mathrm{m}$ thick porous membrane. The carbon nanotubes are typically $30-50 \mathrm{~nm}$ in diameter and hydrophilised by treatment in mineral acid. This type of membrane, when placed into a biphasic organic-aqueous mixture, acts like a surfactant and automatically moves into the liquid | liquid interface (see Figure 16D). Therefore, the interaction of aqueous and organic solutions from opposite sides of the membrane provide a stable and well-defined reaction environment.

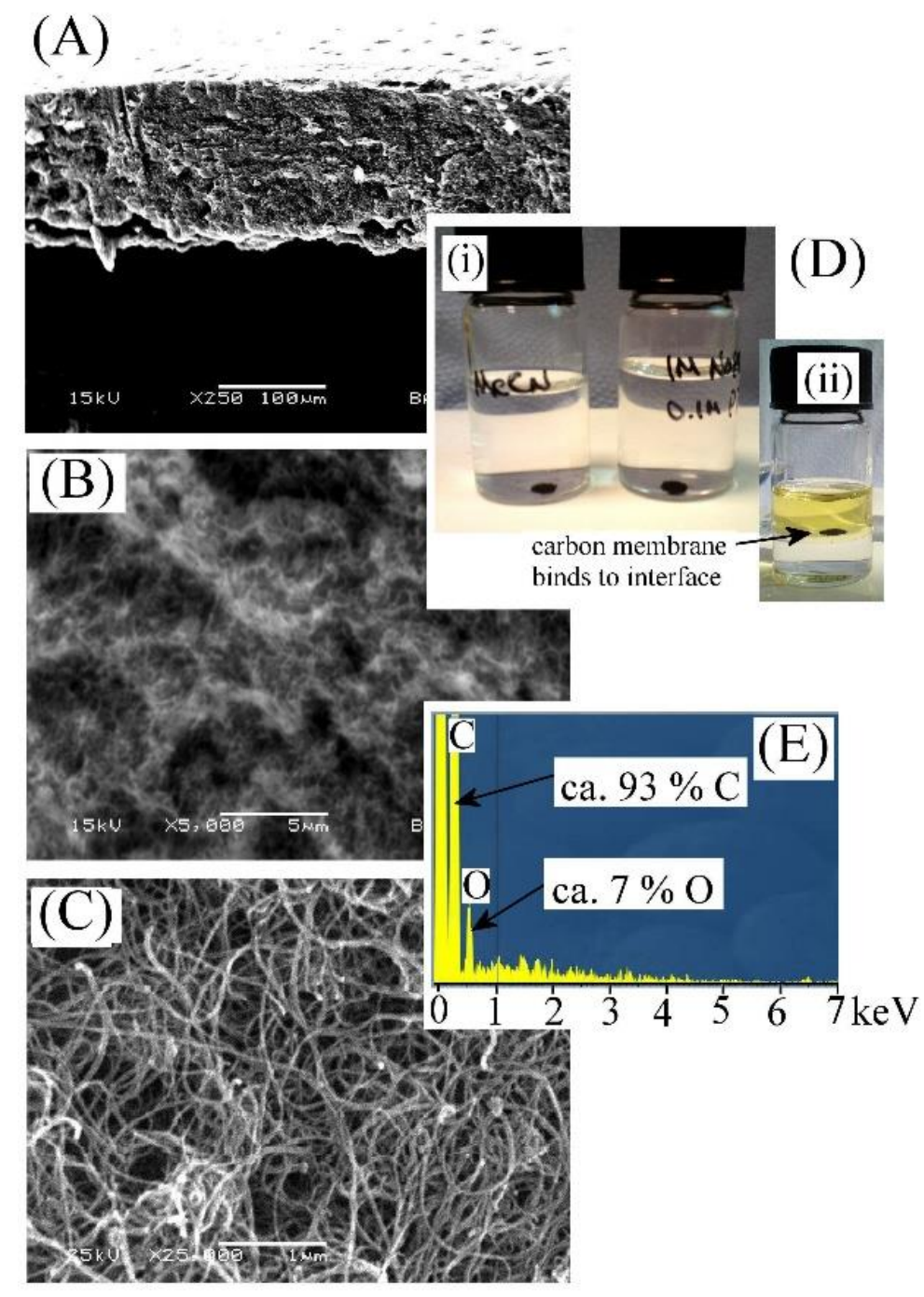

Figure 16. (A-C) Scanning electron micrographs of the "bucky-paper" electrode. (D) Photographic evidence for this nano-carbon electrode sinking to the ground in aqueous and in organic media (i), but being immobilized at the liquid - liquid interface under biphasic conditions (ii). (E) Elemental composition data from energy dispersive X-ray emission analysis. Reproduced with permission from ref. 99. Copyright 2011 Elsevier. 
Electrosynthetic reactions with this type of carbon nanotube membrane were performed in a glass tube (filled with organic phase) in contact to aqueous electrolyte (Figure 17). Aldehyde reduction/reductive dimerization and imine reduction were studied with both starting material and product residing in the organic phase. Two types of products were identified in all cases due to hydrogenation and hydrodimerisation. The formation of these two products was assigned to the reaction zone close to the aqueous phase (a high proton availability causes hydrogenation) and further away from the aqueous phase (a lower proton availability favours hydrodimerisation).
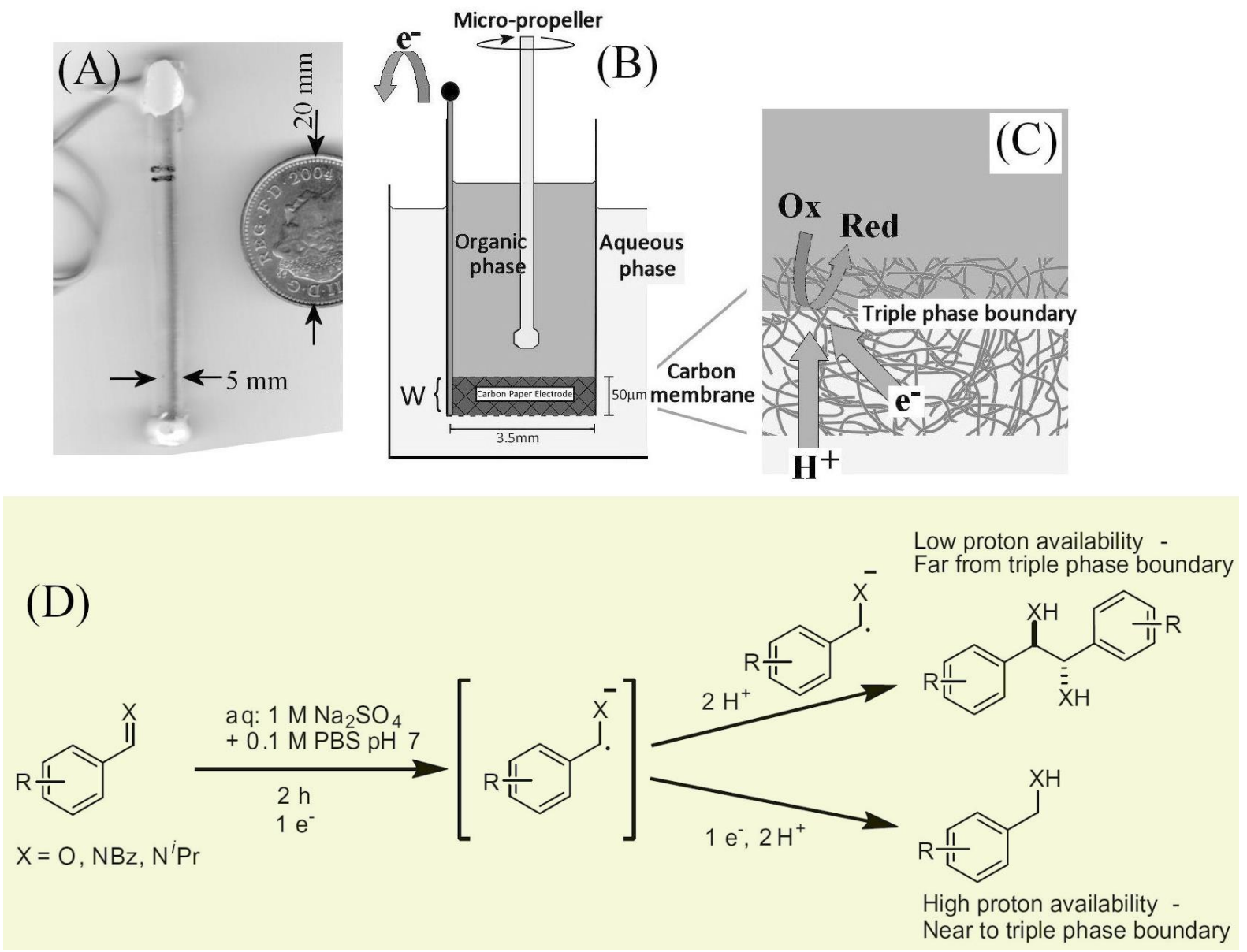

Figure 17. (A) Photograph and $(B, C)$ schematic drawing of the micro-electrolysis cell with bucky-paper working electrode at the bottom. (D) Reaction scheme for biphasic electro-organic transformation of aldehydes and imines. The reactions were performed with a porous buckypaper electrode in the presence of different types of aqueous electrolyte. Reproduced with permission from ref. 100. Copyright 2012 Elsevier.

Other types of porous membranes have been used for liquid | liquid electrolysis. The design in Figure 18 is based on a water-insoluble organic phase permeating through a porous metallic conductor to be electrolysed at the surface in contact to the surrounding aqueous phase. Pioneering work by Gosh et al. ${ }^{101,102,103}$ demonstrated that electrodes (here the anode) can be designed to allow transformation of water-insoluble reagents dissolved in non-polar solvents. 


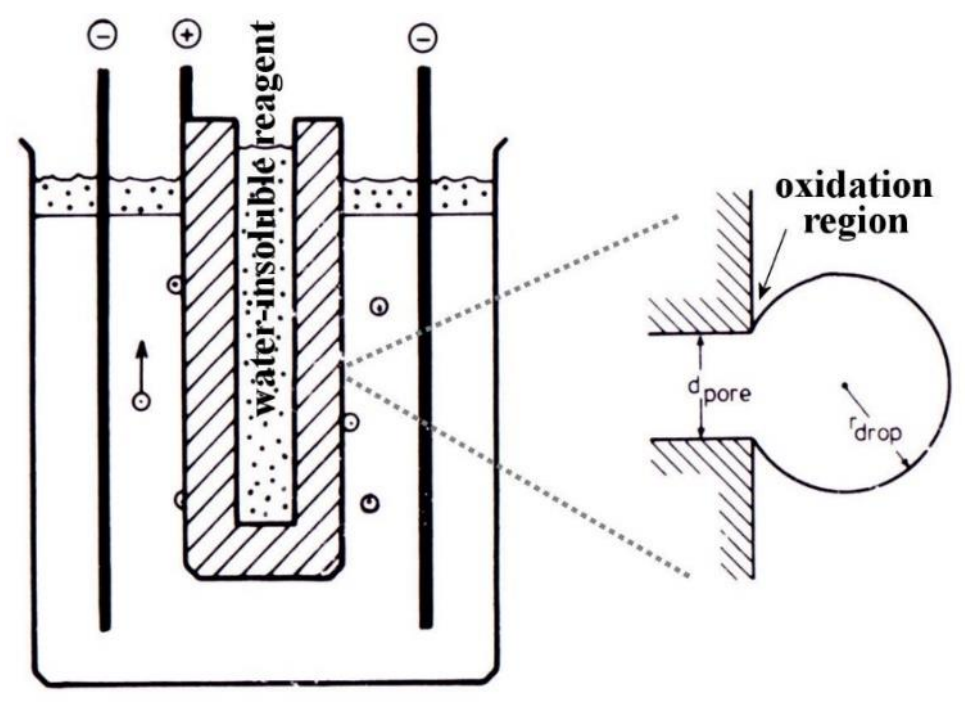

Figure 18. Schematic drawing of the electrolysis cell with highly porous cylindrical anode and conventional cathode. A water-insoluble reagent is dissolved in the organic phase which permeates through small pores to give microdroplets with a high triple phase boundary reaction zone. Reproduced with permission from ref. 104. Copyright 1982 Wiley.

\section{Solid | Liquid | Solid Systems}

In contrast to work on microemulsions and liquid dispersions, there is only very little work on electrosynthetic transformation with dispersed solids, although the potential for application has been realised for many years. ${ }^{105,106}$ In a recent review some of the developments and the fundamental background have been summarised. ${ }^{107}$ Solid-to-solid redox transformations for immobilised solids have been studied intensely for immobilised particles mainly on carbon electrode surfaces. ${ }^{108,109}$ This includes a range of organic and organometallic solids that demonstrate E-type ${ }^{110}$ (redox conversions) as well as EC-type ${ }^{111}$ (redox conversion followed by a chemical reaction step) solid-solid redox transformations.

A good example for the solid state redox conversion is the reduction of indigo to leuco-indigo in the presence of aqueous electrolyte media. ${ }^{112}$ Figure 19 shows three types of processes that are relevant for the voltammetric study of solid indigo micropartilcles adhered to basal plane pyrolytic graphite electrodes. Processes 2 and 3 reflect two-electron, two-proton reduction and oxidation of the microparticles. This is believed to occur only at the surface of particles and Nernstian shifts of peaks with $\mathrm{pH}$ are observed. In contrast, process 1 reflects the reduction of indigo with uptake of $\mathrm{Na}^{+}$and at a $\mathrm{pH}$ of approximately 13 or higher. This process is responsible for bulk conversion and for indigo to convert into a solution-soluble form. Therefore, both the cation intercalation reactivity and the successful conversion of these particles is strongly $\mathrm{pH}$ dependent. 
(A)
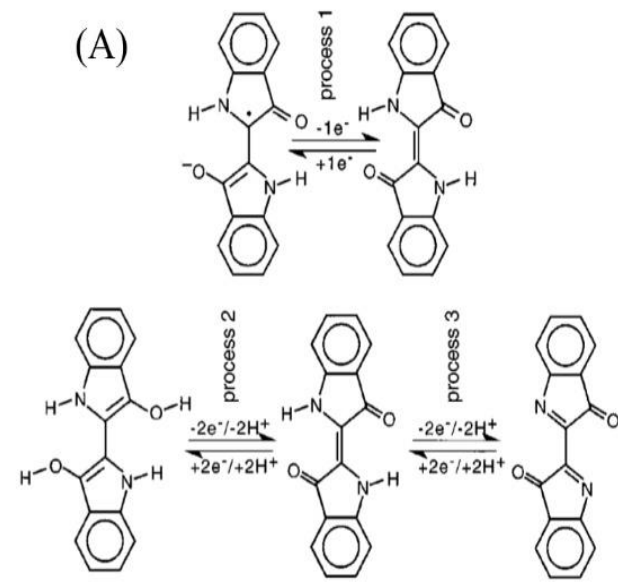

(B)

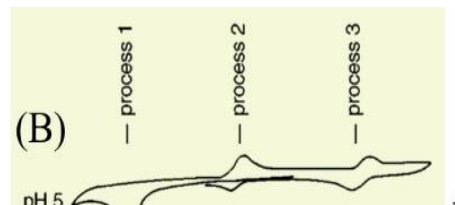

(C)

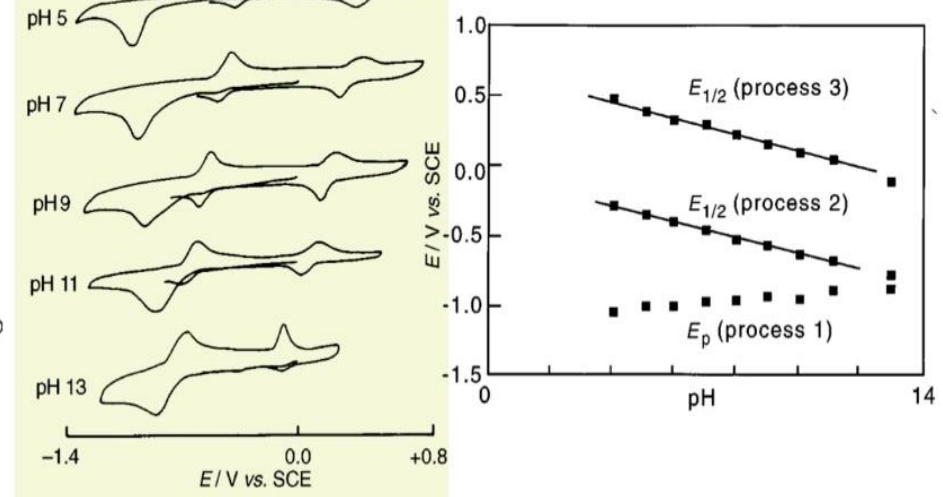

Figure 19. (A) Mechanistic scheme for the reduction and oxidation of indigo. (B) Cyclic voltammograms obtained for microcrystalline indigo mechanically attached to a graphite electrode immersed in an aqueous solution of Britton- Robinson buffer at $\mathrm{pH} 5$ to 11 and in $\mathrm{NaOH}$ at $\mathrm{pH} 13$ (scan rate $0.1 \mathrm{Vs}^{-1}$ ). (C) Plot of $\mathrm{E}_{1 / 2}$ (processes 2 and 3) and $E_{p}$ (process 1) versus $\mathrm{pH}$. Reproduced with permission from ref. 112. Copyright 1997 Royal Society of Chemistry.

The use of surfactants associated with metal redox catalysts has been demonstrated in the oxidation of a slurry of anthracene. Anthraquinone was obtained as the main product when using $\mathrm{Mn}(\mathrm{III} / \mathrm{II})$ in conjunction with the phase transfer catalyst dodecyl-benzene-sulphonate ${ }^{113}$ (Figure 20).
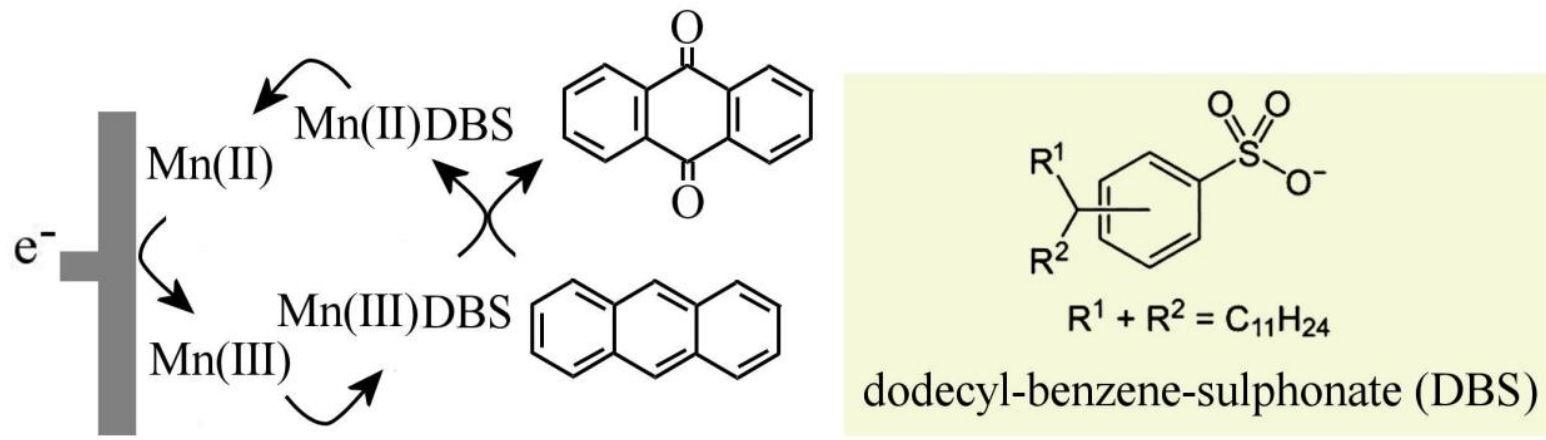

Figure 20. Molecular structure of dodecyl-benzene-sulphonate and schematic drawing of the slurry oxidation of anthracene to anthraquinone.

The formation of solid products is much more common compared to the solid-to-solid conversion. The formation of a solid precipitate of nanoparticles has been observed after electrolysis. ${ }^{114}$ Also, solid pyrans have been electrosynthesised in nanoparticlate form. ${ }^{115}$ Metal nanoparticles can be generated by solution redox mediator electrolysis ${ }^{116}$ and electrosynthesis of MOF particles has been reported. ${ }^{117}$ A review has covered aspects of the topic of solid state transformation in electrosynthesis. ${ }^{118}$ 
In addition to pure solid starting materials reagents on solid supports are attractive. Indirect electrosynthesis with reagents on solid beads has been demonstrated. ${ }^{119}$ Breinbauer and coworkers ${ }^{120}$ have developed several examples with transformation as shown in Figure 21.

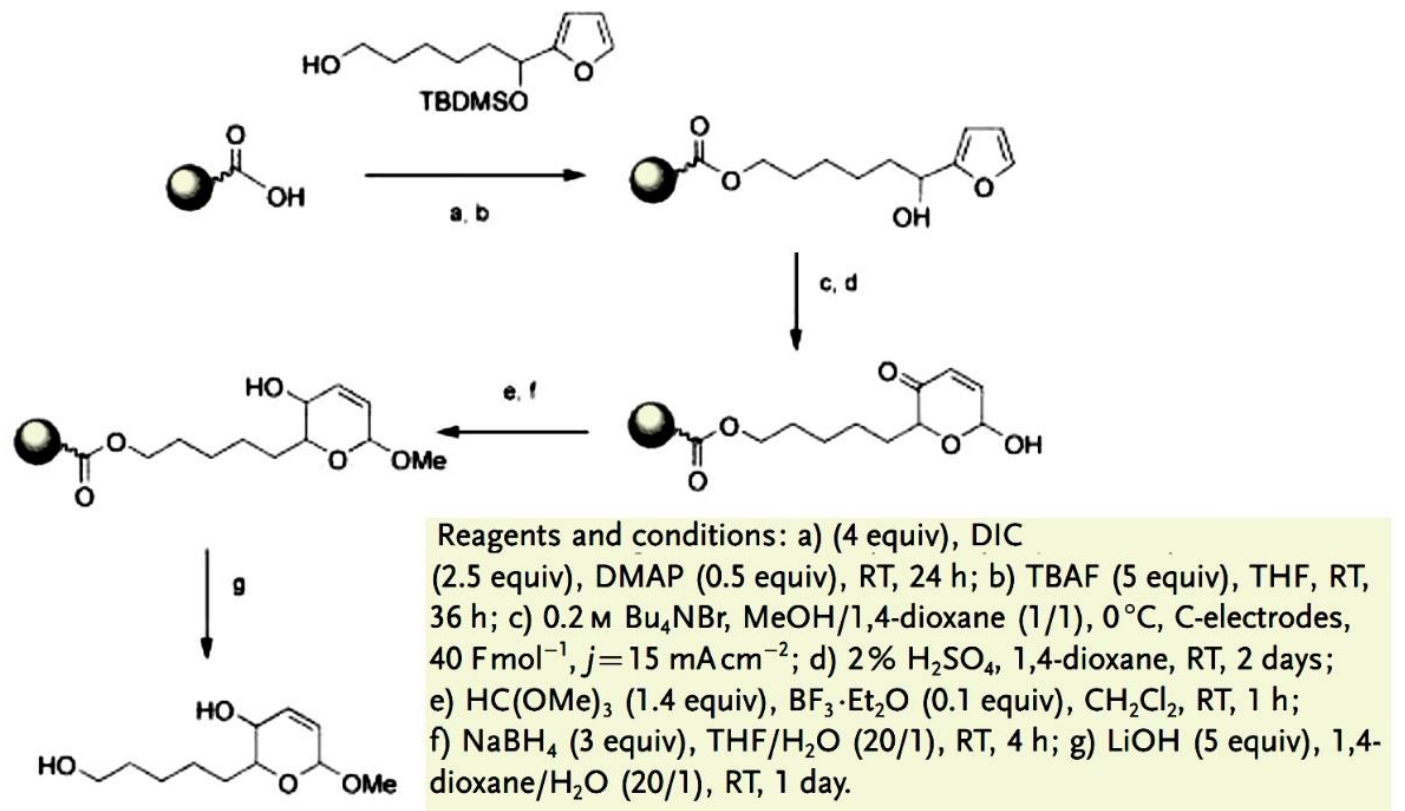

Figure 21. Schematic illustration of a solid state electrosynthetic transformation of furan immobilised onto beads. Reproduced with permission from ref. 120. Copyright 2004 Wiley.

The use of solid supported bases and electrolytes for electrolysis in the absence of "free" electrolyte was developed by Fuchigami and coworkers. ${ }^{121}$ Solid supported electrolytes are attractive for cases where the electrolyte needs to be re-covered and re-used. With a solidsupported electrolyte the product from the electrolysis can be separated from the electrolyte by simple filtration.

The redox catalysed transformation of solid diphenylcarbinol to benzophenone ${ }^{122}$ in aqueous solution has been studied for diphenylcarbinol as solid phase immobilised at the surface of a graphite electrode. A redox catalyst, TEMPO (5 derivatives of TEMPO were investigated and compared) is dissolved in solution to transfer charge, but also to directly react with the solid. Figure 22 shows the reaction sequence in which hydrogen abstraction of the diphenylcarbinol is an important intermediate step. A similar process should be possible also for diphenylcarbinol dispersed in the aqueous phase without the need for immobilisation on the electrode surface. More work will be required to explore solid microparticle suspensions in multiphase electrosynthetic transformations. The reaction progresses only with sufficient mobility or solubility of intermediates to allow a new crystal phase to be nucleated and grow during consumption of the starting material. 


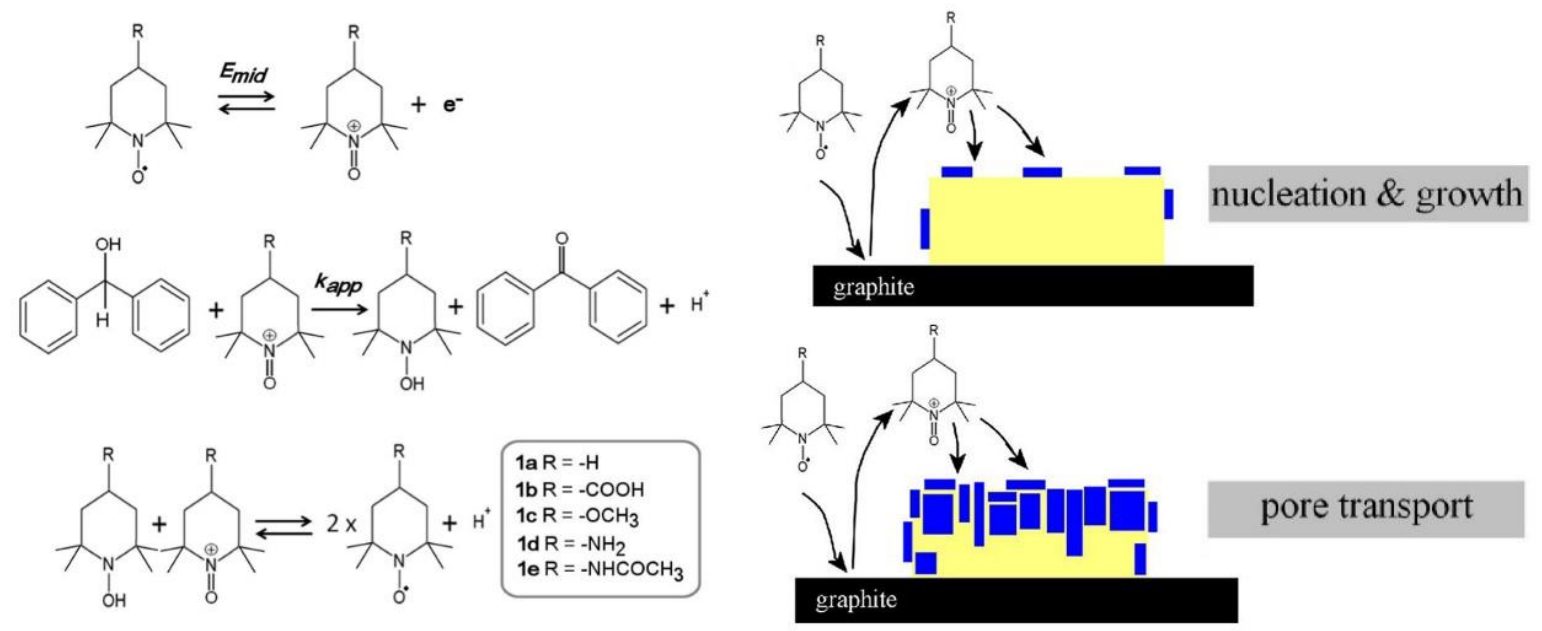

Figure 22. TEMPO-assisted solid-to-solid conversion of diphenylcarbinol into benzophenone electrochemically driven. Scheme of the initial nucleation and growth, and the pore transport stages of the reaction. Reproduced with permission from ref. 122. Copyright 2015 Springer.

\section{Conclusion and Perspectives}

Multiphase electrosynthesis is multi-facetted and may be attractive as a way to perform synthetic transformation under green conditions in aqueous electrolyte media or without added supporting electrolyte. This includes transformation based on suspensions, emulsions, or reactions within gas diffusion electrodes. It may be implicated also in processes based on thin film-modified electrode surfaces where the film phase offers the environment for redox transformation and chemical reaction steps.

When employing the right reaction conditions, multiphase electroorganic transformation are possible and of interest in terms of reaction control and aqueous based clean transformations. The complexity of the additional phase boundaries (or membrane) in these systems offers opportunities for improved catalysis, better/easier separation, and higher performance. Such systems provide much opportunity for the study of fundamental aspects of phase transfer redox processes, but also opportunities for reaction control, green reactor design, and innovation in scale-up.

\section{Author Information}

\section{Biographies}

Frank Marken (Dr. rer. nat. 1992 RWTH Aachen) worked as a Stipendiary Lecturer at the University of Oxford (UK) before moving to the University of Loughborough (UK) in 2000. In September 2004, he was appointed to a Senior Lecturer position at the University of Bath (UK), and in 2011 promoted to a personal chair in Physical Chemistry. His research is focused 
on materials electrochemistry and innovative methods in electroanalysis, in electrosynthesis, and in energy conversion.

Jay D. Wadhawan (M.Chem. 2000, Oxon., D.Phil., 2003, Oxon.) undertook post-doctoral research at Ecole normale supérieure, Paris (France) before moving to The University of Hull (UK) in August, 2005. In August, 2011, he was promoted to a Senior Lecturer position at Hull where he was additionally an Associate Member of the Hull-York Medical School (20122018). He was Vice-Chair in Molecular Electrochemistry at the International Society of Electrochemistry (2011-2014), and at the same time co-editor of Specialist Periodical Reports in Electrochemistry published by the Royal Society of Chemistry. In 2012, he helped establish Chemical Engineering at Hull, and was appointed Reader in Chemical Engineering in August 2019. His research is focused on fundamental electrochemistry for applications in the development of economical and sustainable solutions to industrial problems.

\section{References}

(1) Yan, M.; Kawamata, Y.; Baran, P.S. Synthetic organic electrochemical methods since 2000: on the verge of a renaissance. Chem. Rev. 2017, 117, 13230-13319.

(2) Pletcher, D. Organic electrosynthesis - a road to greater application. A mini review. Electrochem. Commun. 2018, 88, 1-4.

(3) Hammerich, O.; Speiser, B. Organic electrochemistry, 5th ed.; 2015, CRS Press Taylor \& Francis Group: New York.

(4) Zirbes, M.; Waldvogel, S.R. Electro-conversion as a sustainable method for the fine chemical production from the biopolymer lignin. Curr. Opinion Green Sus. Chem. 2018, 14, 19-25.

(5) Ley, S.V.; Fitzpatrick, D.E.; Myers, R.M.; Battilocchio, C.; Ingham, R.J. Machineassisted organic synthesis. Angew. Chem. Inter. Ed. 2015, 54, 10122-10136.

(6) Shatskiy, A.; Lundberg, H.; Karkas, M.D. Organic electrosynthesis: applications in complex molecule synthesis. ChemElectroChem 2019, 6, 4067-4092.

(7) Dai, J.J.; Huang, Y.B.; Fang, C.; Guo, Q.X.; Fu, Y. Electrochemical synthesis of adiponitrile from the renewable raw material glutamic acid. ChemSusChem 2012, 5, $617-620$.

(8) Tang, S.; Liu, Y.C.; Lei, A.W. Electrochemical oxidative cross-coupling with hydrogen evolution: a green and sustainable way for bond formation. Chem 2018, 4, $27-45$. 
(9) Yan, M.; Kawamata, Y.; Baran, P.S. Synthetic organic electrochemistry: calling all engineers. Angew. Chem. Inter. Ed. 2018, 57, 4149-4155.

(10) Chen, Z.P.; Wang, X.L.; Liu, L.C. Electrochemical reduction of carbon dioxide to value-added products: the electrocatalyst and microbial electrosynthesis. Chem. Record 2019, 19, 1272-1282.

(11) Holmberg, K. Organic reactions in microemulsions. Eur. J. Org. Chem. 2007, 5, 731742.

(12) Davies, T.J.; Banks, C.E.; Nuthakki, B.; Rusling, J.F.; France, R.R.; Wadhawan, J.D.; Compton, R.G. Surfactant-free emulsion electrosynthesis via power ultrasound: electrocatalytic formation of carbon-carbon bonds. Green Chem. 2002, 4, 570-577.

(13) Peters, B.K.; Rodriguez, K.X.; Reisberg, S.H.; Beil, S.B.; Hickey, D.P.; Kawamata, Y.; Collins, M.; Starr, J.; Chen, L.R.; Udyavara, S.; Klunder, K.; Gorey, T.J.; Anderson, S.L.; Neurock, M.; Minteer, S.D.; Baran, P.S. Scalable and safe synthetic organic electroreduction inspired by Li-ion battery chemistry. Science 2019, 363, 838841.

(14) Del Campo, F.J.; Neudeck, A.; Compton, R.G.; Marken, F.; Bull, S.D.; Davies, S.G. Low-temperature sonoelectrochemical processes Part 2: Generation of solvated electrons and Birch reduction processes under high mass transport conditions in liquid ammonia. J. Electroanal. Chem. 2001, 507, 144-151.

(15) Birch, A.J. Electrolytic reduction in liquid ammonia. Nature 1946, 158, 60-60.

(16) Holloczki, O.; Macchieraldo, R.; Gleede, B.; Waldvogel, S.R.; Kirchner, B. Interfacial domain formation enhances electrochemical synthesis. J. Phys. Chem. Lett. 2019, 10, 1192-1197.

(17) Cardoso, D.S.P.; Sljukic, B.; Santos, D.M.F.; Sequeira, C.A.C. Organic electrosynthesis: from laboratorial practice to industrial applications. Organic Process Res. Development 2017, 21, 1213-1226.

(18) Turygin, V.V.; Tomilov, A.P. Possible trends in the development of applied electrochemical synthesis of organic compounds. Russ. J. Electrochem. 2015, 51, 999-1020.

(19) Frontana-Uribe, B.A.; Little, R.D.; Ibanez, J.G.; Palma, A.; Vasquez-Medrano, R. Organic electrosynthesis: a promising green methodology in organic chemistry. Green Chem. 2010, 12, 2099-2119.

(20) Rusling, J.F. Green synthesis via electrolysis in microemulsions. Pure Appl. Chem. 2001, 73, 1895-1905. 
(21) Pletcher, D.; Walsh, F.C. Industrial electrochemistry. 1990 Springer Science \& Business Media: London

(22) Karimi, F.; Ashrafizadeh, S.N.; Mohammadi, F. Nylon process parameter impacts on adiponitrile current efficiency and cell voltage of an electromembrane reactor using emulsion-type catholyte. Chem. Engineer. J. 2012, 183, 402-407.

(23) Horn, D.; Rieger J. Organic nanoparticles in the aqueous phase - theory, experiment, and use. Angew. Chem. Inter. Ed. 2001, 40, 4331-4361.

(24) Robbs, P.H.; Rees, N.V. Nanoparticle electrochemistry. Phys. Chem. Chem. Phys. 2016, 18, 24812-24819.

(25) Cheng, W.; Compton, R.G. Electrochemical detection of nanoparticles by 'nano-impact' methods. TRAC-Trends Anal. Chem. 2014, 58, 79-89.

(26) Rees, N.V. Electrochemical insight from nanoparticle collisions with electrodes: A mini-review. Electrochem. Commun. 2014, 43, 83-86.

(27) Peng, Y.Y.; Qian, R.C.; Hafez, M.E.; Long, Y.T. Stochastic collision nanoelectrochemistry: a review of recent developments. ChemElectroChem 2017, 4, 977-985.

(28) Stevenson, K.J.; Tschulik, K. A materials driven approach for understanding single entity nano impact electrochemistry. Curr. Opinion Electrochem. 2017, 6, 38-45.

(29) Cheng, W.; Batchelor-McAuley, C.; Compton, R.G. Organic nanoparticles: mechanism of electron transfer to indigo nanoparticles. ChemElectroChem 2014, 1, 714-717.

(30) Zhou, X.F.; Cheng, W.; Compton, R.G. Contrasts between single nanoparticle and ensemble electron transfer: oxidation and reduction of DPPH nanoparticles in aqueous media. ChemElectroChem 2015, 2, 691-699.

(31) Zhou, X.F.; Cheng, W.; Compton, R.G. Nano-impacts of bifunctional organic nanoparticles. Nanoscale 2014, 6, 6873-6878.

(32) Montoto, E.C.; Nagarjuna, G.; Hui, J.S.; Burgess, M.; Sekerak, N.M.; HernandezBurgos, K.; Wei, T.S.; Kneer, M.; Grolman, J.; Cheng, K.J.; Lewis, J.A.; Moore, J.S.; Rodriguez-Lopez, J. Redox active colloids as discrete energy storage carriers. J. Amer. Chem. Soc. 2016, 138, 13230-13237.

(33) Cheng, W.; Compton, R.G. Investigation of single-drug-encapsulating liposomes using the nano-impact method. Angew. Chem. Inter. Ed. 2014, 53, 13928-13930.

(34) Lebegue, E.; Anderson, C.M.; Dick, J.E.; Webb, L.J.; Bard, A.J. Electrochemical detection of single phospholipid vesicle collisions at a Pt ultramicroelectrode. Langmuir 2015, 31, 11734-11739. 
(35) Phan, N.T.N.; Li, X.C.; Ewing, A.G. Measuring synaptic vesicles using cellular electrochemistry and nanoscale molecular imaging. Nature Rev. Chem. 2017, 1, UNSP 0048.

(36) Amatore, C.; Arbault, s.; Bonifas, I.; Bouret, Y.; Erad, M.; Guille, M. Dynamics of full fusion during vesicular exocytotic events: release of adrenaline chromaffin cells. ChemPhysChem 2003, 4, 147-154.

(37) Li, X.C.; Dunevall, J.; Ren, L.; Ewing, A.G. Mechanistic aspects of vesicle opening during analysis with vesicle impact electrochemical cytometry. Anal. Chem. 2017, 89, 9416-9423.

(38) Liu, Y.; Xu, C.; Yu, P.; Chen, X.W.; Wang, J.H.; Mao, L.Q. Counting and sizing of single vesicles/liposomes by electrochemical events. ChemElectroChem 2018, 5, 2954-2962.

(39) Amatore, C.; Arbault, S.; Bonifas, I.; Bouret, Y.; Erad, M.; Ewing, A.G.; Sombers, L.A. Correlation between vesicle quantal size and fusion pore release in chromaffin cell exocytosis. Biophys. J. 2005, 88, 4411-4420.

(40) McKenzie, K.J.; Marken, F. Direct electrochemistry of nanoparticulate $\mathrm{Fe}_{2} \mathrm{O}_{3}$ in aqueous solution and adsorbed onto tin-doped indium oxide. Pure Appl. Chem. 2001, $73,1885-1894$.

(41) Watkins, J.D.; Bull, S.D.; Marken, F. Sono-droplet ultrasound mobilization of liquid/liquid/solid triple-phase boundary redox systems. J. Phys. Chem. C 2009, 113, $15629-15633$.

(42) Watkins, J.D.; Amemiya, F.; Atobe, M.; Bulman-Page, P.C.; Marken, F. Liquid | liquid biphasic electrochemistry in ultra-turrax dispersed acetonitrile $\mid$ aqueous electrolyte systems. Electrochim. Acta 2010, 55, 8808-8814.

(43) Deunf, E.; Labbe, E.; Verpeaux, J.N.; Buriez, O.; Amatore, C. Direct electrochemical reduction of organic halide droplets dispersed in water. $R S C A d v$. 2012, 2, 53985402.

(44) Banks, C.E.; Rees, N.V.; Compton, R.G. Sonoelectrochemistry in acoustically emulsified media. J. Electroanal. Chem. 2002, 535, 41-47.

(45) Atobe, M.; Ikari, S.; Nakabayashi, K.; Amemiya, F.; Fuchigami, T. Electrochemical reaction of water-insoluble organic droplets in aqueous electrolytes using acoustic emulsification. Langmuir 2010, 26, 9111-9115. 
(46) Nakabayashi, K.; Fuchigami, T.; Atobe, M. Tandem acoustic emulsion, an effective tool for the electrosynthesis of highly transparent and conductive polymer films. Electrochim. Acta 2013, 110, 593-598.

(47) Wadhawan, J.D.; Del Campo, F.J.; Compton, R.G.; Foord, J.S.; Marken, F.; Bull, S.D.; Davies, S.G.; Walton, D.J.; Ryley, S. Emulsion electrosynthesis in the presence of power ultrasound biphasic Kolbe coupling processes at platinum and boron-doped diamond electrodes. J. Electroanal. Chem. 2001, 507, 135-143.

(48) Mackay, R.A.; Texter, J. Electrochemistry in Colloids and Dispersions. 1992, Weinheim, Wiley-VCH Verlag GmbH.

(49) Wadhawan, J.D.; Marken, F.; Compton, R.G. Biphasic sonoelectrosynthesis. A review. Pure Appl. Chem. 2001, 73, 1947-1955.

(50) Laurent E.; Rauniyar, G.; Thomalla, M. Anodic substitutions in emulsions under phase transfer catalysis conditions. I. Cyanation of dimethoxybenzenes. J. Appl. Electrochem. 1984, 14, 741-748.

(51) Blackburn, R.S.; Bechtold, T.; John, P. The development of indigo reduction methods and pre-reduced indigo products. Coloration Technol. 2009, 125, 193-207.

(52) Roessler, A.; Crettenand, D.; Dossenbach, O.; Marte, W.; Rys, P. Direct electrochemical reduction of indigo. Electrochim. Acta 2002, 47, 1989-1995.

(53) Roessler, A.; Crettenand, D. Direct electrochemical reduction of vat dyes in a fixed bed of graphite granules. Dyes Pigments 2004, 63, 29-37.

(54) Degrand, C.; Nour, M. Electrochemical reduction of seleniumin aprotic solvents application to the selective electrosynthesis of dialkyl selenides and or deselenides. J. Electroanal. Chem. 1985, 190, 213-223.

(55) Torii, S. Novel methodologyin electroorganic synthesis - Potentiality in electroreduction of sulphur, selenium, and tellurium compounds. J. Synth. Org. Chem. Japan 1990, 48, 553-570.

(56) Francke, R.; Little, R.D. Redox catalysis in organic electrosynthesis: basic principles and recent developments. Chem. Soc. Rev. 2014, 43, 2492-2521.

(57) Rokitskaya, T.I.; Murphy, M.P.; Skulachev, V.P.; Antonenko, Y.N. Ubiquinol and plastoquinol triphenylphosphonium conjugates can carry electrons through phospholipid membranes. Bioelectrochem. 2016, 111, 23-30.

(58) Wain, A.J.; Wadhawan, J.D.; Compton, R.G. Electrochemical studies of vitamin $\mathrm{K}_{1}$ microdroplets: electrocatalytic hydrogen evolution. ChemPhysChem 2003, 4, 974-982. 
(59) Turcanu, A.; Bechtold, T. Indirect cathodic reduction of dispersed indigo by 1,2dihydroxy-9,10-anthraquinone-3-sulphonate (Alizarin Red S). J. Solid State Electrochem. 2011, 15, 1875-1884.

(60) Vuorema, A.; John, P.; Keskitalo, M.; Mahon, M.F.; Kulandainathan, M.A.; Marken, F. Anthraquinone catalysis in the glucose-driven reduction of indigo to leuco-indigo. Phys. Chem. Chem. Phys. 2009, 11, 1816-1824.

(61) Floner, D.; Laglaine, L.; Moinet, C. Indirect electrolysis involving an ex-cell two-phase process. Reduction of nitrobenzenes with a titanium complex as mediator. Electrochim. Acta 1997, 42, 525-529.

(62) Tanaka, H.; Kuroboshi, M.; Mitsudo, K. Design of redox-mediatory systems for electro-organic synthesis. Electrochemistry 2009, 77, 1002-1009.

(63) Chiba, K.; Tada, M. Electrochemical generation and cycloaddition reaction of unstable intermediates in hydrophobic fields. J. Synth. Org. Chem. Japan 1996, 54, 686-695.

(64) Raynal, F.; Barhdadi, R.; Perichon, J.; Savall, A.; Troupel, M. Water as solvent for nickel-2,2 '-bipyridine-catalysed electrosynthesis of biaryls from haloaryls. Adv. Synth. Catal. 2002, 344, 45-49.

(65). Jing, R.; Tang, J.; Zhang, Q.; Chen, L.; Ji, D.X.; Yu, F.W.; Lu, M.Z.; Ji, J.B.; Wang, J.L. An insight into the intensification of aqueous/organic phase reaction by the addition of magnetic polymer nanoparticles. Chem. Engineer. J. 2015, 280, 265-274.

(66) Anelli, P.L.; Biffi, C.; Montanari, F.; Quici, S. Fast and selective oxidation of primary alcohols to aldehydes or to carboxylic-acids and of secondary alcohols to ketones mediated by oxoammonium salts under 2-phase conditions. J. Org. Chem. 1987, 52, 2559-2562.

(67) Tang, J.; Zhang, Q.; Hu, K.C.; Zhang, P.; Wang, J.L. Novel high TEMPO loading magneto-polymeric nanohybrids: An efficient and recyclable Pickering interfacial catalyst. J. Catal. 2017, 353, 192-198.

(68) Budnikova, Y.H. Metal complex catalysis in organic electrosynthesis. Uspekhi Khimi 2002, 71, 126-158.

(69) Zhou, D.L.; Carrero, H.; Rusling, J.F. Radical versus anionic pathway in mediated electrochemical reduction of benzyl bromide in a bicontinuous microemulsion. Langmuir 1996, 12, 3067-3074.

(70) Li, J.; Chen, G.X.; Zhu, Y.Y.; Liang, Z.; Pei, A.; Wu, C.L.; Wang, H.X.; Lee, H.R.; Liu, K.; Chu, S.; Cui, Y. Efficient electrocatalytic $\mathrm{CO}_{2}$ reduction on a three-phase interface. Nature Catal. 2018, 1, 592-600. 
(71) Vennekoetter, J.B.; Sengpiel, R.; Wessling, M. Beyond the catalyst: How electrode and reactor design determine the product spectrum during electrochemical $\mathrm{CO}_{2}$ reduction. Chem. Engineer. J. 2019, 364, 89-101.

(72) Anandhakumar, S.; Sripriya, R.; Chandrasekaran, M.; Govindu, S.; Noel, M. Electrocarboxylation and related radical coupling processes of aryl and benzyl halides in microemulsion. J. Appl. Electrochem. 2009, 39, 463-465.

(73) Losiewicz, B.; Lasia, A. Study of the hydrogen absorption/diffusion in $\mathrm{Pd}_{80} \mathrm{Rh}_{20}$ alloy in acidic solution. J. Electroanal. Chem. 2018, 822, 153-162.

(74) Sherbo, R.S.; Delima, R.S.; Chiykowski, V.A.; MacLeod, B.P.; Berlinguette, C.P. Complete electron economy by pairing electrolysis with hydrogenation. Nature Catal. 2018, 1, 501-507.

(75) Sherbo, R.S.; Kurimoto, A.; Brown, C.M.; Berlinguette, C.P. Efficient electrocatalytic hydrogenation with a palladium membrane reactor. J. Amer. Chem. Soc. 2019, 141, $7815-7821$.

(76) Shirai, M.; Arai, M. Hydrogenation of furan with hydrogen atoms permeating through a palladium membrane. Langmuir 1999, 15, 1577-1578.

(77) Gryaznov, V.M. Surface catalytic properties and hydrogen diffusion in palladium alloy membranes. Zeitschr. Physikal. Chemie 1986, 147, 123-32.

(78) Gryaznov, V.M. Hydrogen permeable palladium membrane catalysts. An aid to the efficient production of ultrapure chemicals and pharmaceuticals. Platinum Metals Rev. 1986, 30, 68-72.

(79) Serov, Y.M.; Zhernosek, V.M.; Gulyanova, S.G.; Gryaznov, V.M. Kinetics of carbon dioxide hydrogenation over a hydrogen-permeable palladium-ruthenium membrane catalyst coated with nickel. 2. Kinetics Catalysis 1983, 24, 303-306.

(80) Paglieri, S.N.; Way, J.D. Innovations in palladium membrane research. Separation Purification Methods 2002, 31, 1-169.

(81) Hoormann, D.; Kubon, C.; Jorissen, J.; Kroner, L.; Putter, H. Analysis and minimization of cell voltage in electro-organic syntheses using the solid polymer electrolyte technology. J. Electroanal. Chem. 2001, 507, 215-225.

(82) Joerissen, J. Ion exchange membranes as solid polymer electrolytes (spe) in electroorganic synthesis without supporting electrolytes. Electrochim. Acta 1996, 41, 553-62. 
(83) Inoue, H.; Higashiyama, K.; Higuchi, E.; Iwakura, C. A dechlorination system for 4chlorotoluene using a two-compartment cell separated by a palladized ion exchange membrane. J. Electroanal. Chem. 2003, 560, 87-91.

(84) Iwakura, C.; Tsuchiyama, Y.; Higashiyama, K.; Higuchi, E.; Inoue, H. Successive hydrogenation and dechlorination systems using palladized ion exchange membranes. J. Electrochem. Soc. 2004, 151, D1-D5.

(85) Lei, T.; Zhao, K.S. Application of ion-exchange membranes as solid polymer electrolyte to electroorganic syntheses. Мо Кехие Yи Jishu 1999, 19, 19-24.

(86) Ogumi, Z.; Mizoe, T.; Zhen, C.; Takehara, Z. Application of the SPE method to organic electrochemistry. X. Behavior of the manganese redox couple incorporated in platinum-Nafion and their mediatory oxidation of cinnamyl alcohol to cinnamaldehyde. Bull. Chem. Soc. Japan 1990, 63, 3365-3368.

(87) Saez, A.; Garcia-Garcia, V.; Solla-Gullon, J.; Aldaz, A.; Montiel, V. Electrocatalytic hydrogenation of acetophenone using a polymer electrolyte membrane electrochemical reactor. Electrochim. Acta 2013, 91, 69-74.

(88) Ahn, S.D.; Marken F. Biphasic and emulsion electro-organic syntheses. In Modern Electrosynthetic Methods in Organic Chemistry - New Directions in Organic \& Biological Chemistry. Marken F.; Atobe M. (eds.) 2018, Taylor \& Francis, London.

(89) Banks, C.E.; Davies, T.J.; Evans, R.G.; Hignett, G.; Wain, A.J.; Lawrence, N.S.; Wadhawan, J.D.; Marken, F.; Compton, R.G. Electrochemistry of immobilised redox droplets: Concepts and applications. Phys. Chem. Chem. Phys. 2003, 5, 40534069 .

(90) Pletcher, D.; Green, R.A.; Brown, R.C.D. Flow electrolysis cells for the synthetic organic chemistry laboratory. Chem. Rev. 2018, 118, 4573-4591.

(91) Arai, K.; Watts, K.; Wirth, T. Difluoro- and trifluoromethylation of electron-deficient alkenes in an electrochemical microreactor. Chem. Open 2014, 3, 23-28.

(92) He, P.; Watts, P.; Marken, F.; Haswell, S.J. Scaling out of electrolyte-free electrosynthesis in a micro-gap flow cell. Lab Chip 2007, 7, 141-143.

(93) Kaluza, D.; Adamiak, W.; Opallo, M.; Jonsson-Niedziolka, M. Comparison of ion transfer thermodynamics at microfluidic and droplet-based three phase electrodes. Electrochim. Acta 2014, 132, 158-164.

(94) Aota, A. Applications of multiphase microflows to chemical processes. Bunseki Kagaku 2014, 63, 299-310. 
(95) Kaluza, D.; Adamiak, W.; Kalwarczyk, T.; Sozanski, K.; Opallo, M.; JonssonNiedziolka, M. Anomalous effect of flow rate on the electrochemical behavior at a liquid | liquid interface under microfluidic conditions. Langmuir 2013, 29, 1603416039.

(96) MacDonald, S.M.; Watkins, J.D.; Bull, S.D.; Davies, I.R.; Gu, Y.; Yunus, K.; Fisher, A.C.; Page, P.C.B.; Chan, Y.; Elliott, C.; Marken, F. Two-phase flow electrosynthesis: Comparing N-octyl-2-pyrrolidone-aqueous and acetonitrile-aqueous three-phase boundary reactions. J. Phys. Org. Chem. 2009, 22, 52-58.

(97) MacDonald, S.M.; Watkins, J.D.; Gu, Y.; Yunus, K.; Fisher, A.C.; Shul, G.; Opallo, M.; Marken, F. Electrochemical processes at a flowing organic solvent | aqueous electrolyte phase boundary. Electrochem. Commun. 2007, 9, 2105-2110.

(98) Cognet, P.; Berlan, J.; Lacoste, G.; Fabre, P.L.; Jud, J.M. Application of metallic foams in an electrochemical pulsed flow reactor .2. Oxidation of benzyl alcohol. J. Appl. Electrochem. 1996, 26, 631-637.

(99) Watkins, J.D.; Ahn, S.D.; Taylor, J.E.; Bull, S.D.; Bulman-Page, P.C.; Marken, F. Liquid-liquid electro-organo-synthetic processes in a carbon nanofibre membrane microreactor: Triple phase boundary effects in the absence of intentionally added electrolyte. Electrochim. Acta 2011, 56, 6764-6770.

(100) Watkins, J.D.; Taylor, J.E.; Bull, S.D.; Marken, F. Mechanistic aspects of aldehyde and imine electro-reduction in a liquid-liquid carbon nanofiber membrane microreactor. Tetrahedron Lett. 2012, 53, 3357-3360.

(101) Gosh, J.C.; Bhattacharyya, S.K.; Muthanna, M.S.; Mitra, C.R. Electrolytic reactions on porous carbon anodes: I. The preparation of $p$-benzoquione by the oxidation of benzene. J. Sci. Ind. Res. (India), 1952, 11B, 356-360.

(102) Gosh, J.C.; Bhattacharyya, S.K.; Rao, M.R.A.; Muthanna, M.S.; Patnaik, P.B. Electrolytic reactions on porous carbon anodes: II. The preparation of chlorobenzene from benzene. J. Sci. Ind. Res. (India) 1952, 11B, 361-364.

(103) Fenton, J.M.; Alkire, R.C. Mass-transport in flow-through porous-electrodes with 2-phase liquid-liquid flow. J. Electrochem. Soc. 1988, 135, 2200-2209.

(104) Feess, H.; Wendt, H. Performance of electrolysis with two-phase electrolyte. Techniques of electro-organic synthesis. Part III, Weinberg, N.L.; Tilak B.V. (eds.) John Wiley \& Sons, New York, 1982, p. 99.

(105) Pletcher, D., Indirect electrolysis involving phase transfer catalysis. Little, R.D.; Weinberg, N.L. (eds.) Electroorganic Synthesis 1991, 255-62. 
(106) Halls, J.E.; Wadhawan, J.D. Biphasic voltammetry of $N, N, N^{\prime}, N^{\prime}$-tetraphenyl-paraphenylenediamine microdroplets, microparticles and microparticle suspensions. Electroanalysis 2011, 23, 997-1006.

(107) Doménech-Carbó, A. Solid-to-Solid Transformations in Organic Electrosynthesis. Modern Electrosynthetic Methods in Organic Chemistry - New Directions in Organic \& Biological Chemistry. Marken F.; Atobe M. (eds.) 2018, Taylor \& Francis, London.

(108) Scholz, F.; Meyer, B. Electrochemical solid-state analysis - State-of-the-art. Chem. Soc. Rev. 1994, 23, 341-347.

(109) Grygar, T.; Marken, F.; Schröder, U.; Scholz, F. Electrochemical analysis of solids. A review. Coll. Czech. Chem. Commun. 2002, 67, 163-208.

(110) Bond, A.M.; Marken, F.; Williams, C.T.; Beattie, D.A.; Keyes, T.E.; Forster, R.J.; Vos, J.G. Unusually fast electron and anion transport processes observed in the oxidation of "electrochemically open" microcrystalline $\left.\left[\left\{\mathrm{M}(\text { bipy })_{2}\right\}\{\mathrm{M} \text { '(bipy })_{2}\right\}(\mu-\mathrm{L})\right]\left(\mathrm{PF}_{6}\right)_{2}$ complexes (M, M ' = Ru, Os; bipy=2,2 '-bipyridyl; L=1,4-dihydroxy-2,5-bis(pyrazol-1yl)benzene dianion) at a solid-electrode-aqueous electrolyte interface. J. Phys. Chem. B 2000, 104, 1977-1983.

(111) Bond, A.M.; Colton, R.; Daniels, F.; Fernando, D.R.; Marken, F.; Nagaosa, Y.; Vansteveninck, R.F.M.; Walter, J.N. Voltammetry, electron-microscopy, and X-ray electron-probe microanalysis at the electrode aqueous-electrolyte interface of solid microcrystalline cis- $\mathrm{Cr}(\mathrm{CO})_{2}(\mathrm{DPE})_{2}$ and trans- $\mathrm{Cr}(\mathrm{CO})_{2}(\mathrm{DPE})_{2}$ and trans$\left[\mathrm{Cr}(\mathrm{CO})_{2}(\mathrm{DPE})_{2}\right]^{+}$complexes $\left(\mathrm{DPE}=\mathrm{Ph}_{2} \mathrm{PCH}_{2} \mathrm{CH}_{2} \mathrm{PPh}_{2}\right)$ mechanically attached to carbon electrodes. J. Amer. Chem. Soc. 1993, 115, 9556-9562.

(112) Bond, A.M.; Marken, F.; Hill, E.; Compton, R.G.; Hügel, H. The electrochemical reduction of indigo dissolved in organic solvents and as a solid mechanically attached to a basal plane pyrolytic graphite electrode immersed in aqueous electrolyte solution. J. Chem. Soc. Perkin Trans. 2, 1997, 9, 1735-1742.

(113) Chou, T.C.; Cheng, C.H. Indirect anodic oxidation of anthracene to anthraquinone in a slurry electrolyte systems in the presence of both surfactant and redox mediator. J. Appl. Electrochem. 1992, 22, 743-748.

(114) Makarem, S.; Fakhari, A.R.; Mohammadi, A.A. Electro-organic synthesis: an efficient method for the preparation of nanosized particles of phthalazine derivatives via one-pot multicomponent reactions. Anal. Bioanal. Chem. Res. 2015, 2, 85-89. 
(115) Makarem, S.; Mirza, B.; Darvish, Z.M.; Notash, N.A.; Ashrafi, S. Organic electrosynthesis: a promising alternative methodology for the synthesis of nanosized particles of pyrans. Anal. Bioanal. Chem. Res. 2019, 6, 231-240.

(116) Nasretdinova, G.R.; Osin, Y.N.; Gubaidullin, A.T.; Yanilkin, V.V. Methylviologen mediated electrosynthesis of palladium nanoparticles stabilized with CTAC. J. Electrochem. Soc. 2016, 163, G99-G106.

(117) Senthil Kumar, R.; Senthil Kumar, S.; Kulandainathan, A.M. Efficient electrosynthesis of highly active $\mathrm{Cu}_{3}(\mathrm{BTC})_{2}-\mathrm{MOF}$ and its catalytic application to chemical reduction. Microporous Mesoporous Mater. 2013, 168, 57-64.

(118) Simonet, J. Electrochemistry applied to organic synthesis: principles and main achievements. Bard, A.J.; Stratmann, M. (eds.), Encyclopedia of Electrochemistry 2007, 5, 317-376.

(119) Nad, S.; Breinbauer, R. Electroorganic synthesis of 2,5-dialkoxydihydrofurans and pyridazines on solid phase using polymer beads as supports. Synthesis $\mathbf{2 0 0 5}, 20$, 3654-3665.

(120) Nad, S.; Breinbauer, R. Electroorganic synthesis on the solid phase using polymer beads as supports. Angew. Chem. Inter. Ed. 2004, 43, 2297-2299.

(121) Fuchigami, T.; Tajima, T. Development of new methodologies toward green sustainable organic electrode processes. Electrochemistry 2006, 74, 585-589.

(122) Kaluza, D.; Jonsson-Niedziolka, M.; Ahn, S.D.; Owen, R.E.; Jones, M.D.; Marken, F. Solid-solid EC' TEMPO-electrocatalytic conversion of diphenylcarbinol to benzophenone. J. Solid State Electrochem. 2015, 19, 1277-1283. 